This item was submitted to Loughborough's Research Repository by the author.

Items in Figshare are protected by copyright, with all rights reserved, unless otherwise indicated.

\title{
Factors affecting employees' knowledge-sharing behaviour in the virtual organisation from the perspectives of well-being and organisational behaviour
}

\section{PLEASE CITE THE PUBLISHED VERSION}

http://dx.doi.org/10.1016/j.chb.2016.07.011

\section{PUBLISHER}

(C) Elsevier

\section{VERSION}

AM (Accepted Manuscript)

\section{PUBLISHER STATEMENT}

This work is made available according to the conditions of the Creative Commons Attribution-NonCommercialNoDerivatives 4.0 International (CC BY-NC-ND 4.0) licence. Full details of this licence are available at: https://creativecommons.org/licenses/by-nc-nd/4.0/

\section{LICENCE}

CC BY-NC-ND 4.0

\section{REPOSITORY RECORD}

Chumg, Hao-Fan, Jonathan S. Seaton, Louise Cooke, and Wen-Yu Ding. 2019. "Factors Affecting Employees' Knowledge-sharing Behaviour in the Virtual Organisation from the Perspectives of Well-being and Organisational Behaviour". figshare. https://hdl.handle.net/2134/22782. 


\title{
Factors Affecting Employees' Knowledge-sharing Behaviour in the Virtual Organisation from the Perspectives of Well-being and Organisational Behaviour
}

\begin{abstract}
Drawing on the concept of organisational behaviour, this research augments the concepts of social capital theory and organisational culture with one pioneering precursor and mediator, the sense of well-being, to develop an integrative understanding of the factors affecting individuals' knowledge-sharing behaviour within the more complex context of the virtual organisation of Taiwanese Non-governmental Organisations (NGOs). A field survey of 131 employees from the selected virtual organisation was analysed using Structural Equation Modeling (SEM) to examine the outcomes empirically. Our research offers a persuasive body of evidence supporting the notion that increasing employees' sense of well-being can successfully form a bridge that can connect social capital tendency, organisational culture and employees’ knowledge-sharing behaviour. Surprisingly, and contrary to common belief, the integrated model shows that social capital tendency seems to play a more important role than organisational culture in affecting employees' sense of well-being within the virtual organisation in a Chinese cultural context. Consequently, this research reveals the subtle interplay of employees' sense of well-being, social capital tendency, organisational culture and knowledge-sharing behaviour, while the in-depth analysis provides strong support for knowledge management research and practice.
\end{abstract}

Keywords: Knowledge-sharing Behaviour, Social Capital Theory, Organisational Culture, Virtual Organisation, Organisational Behaviour, Sense of Well-being, Structural Equation Modeling (SEM).

\section{Introduction}

With the advent of economic globalisation and the Knowledge-Based Economy (KBE), successful knowledge management (KM) has become a critical determinant affecting the effectiveness and performance of an organisation (Sharma, Singh, \& Neha, 2012). Meanwhile, effective knowledge sharing is of great importance as a foundation stone in knowledge management (Sharma et al., 2012). This is mainly because, through effective knowledge-sharing among employees, organisations can increase their profile and gain market opportunities, enhancing performance and increasing their competitive advantage in an uncertain environment (Lin, 2007). As a result, a great many enterprises are extremely keen to draw new knowledge from organisational knowledge workers in order to maintain the sustainable development of their companies (Liu, Raahemi, \& Benyoucef, 2011). 
However, a review of the literature concerning individuals' knowledge-sharing behaviour shows that the motives and factors involved in behaviour such as knowledge sharing are still regarded as difficult to understand comprehensively and explore in great detail (Holste \& Fields, 2010; Wang \& Hou, 2015). Chief among the reasons is that individuals' knowledge-sharing behaviour goes against human nature as people think their knowledge is valuable and important (Davenport \& Prusak, 1998). Hence, organisations' employees often feel reluctant to share their knowledge because they fear that they might lose their jobs or that their status in the organisation might be jeopardised because of their knowledge sharing (Wasko \& Faraj, 2005). In this respect, it is inevitable, perhaps even instinctive, that, since individuals possess their own unique and precious knowledge, they may be reluctant to share it, particularly in a virtual organisation (Burn \& Ash, 2000). Moreover, Pfeffer and Sutton (1999) indicated that the knowledge management established in many organisations focuses merely on technology, and in particular, information technology. Finally, Davenport (1994, p.120) stated that “...in most companies, many managers still believe that once the right technology is in place, the appropriate information-sharing behaviour will inevitably follow" while Dixon (2000) stated that "build it and they will come" is a myth of knowledge sharing. Yet, these views seem rather to over-emphasise the important position of knowledge management with regard to information technology (Leonardi \& Treem, 2012). Clearly, the biggest challenge in building successful knowledge management is the willingness for members to share their knowledge with others. Recently, rather than focusing on negative psychology, an increasing number of research studies have instead begun to investigate the impacts of an individual's positive psychology on his/her knowledge-sharing behaviour. For instance, Wang and Hou (2015) adopted the perspectives of self-determination and altruism to explore relevant factors with regard to knowledge-sharing behaviour and illustrated that these factors were positively associated with knowledge-sharing behavior. Wasko and Faraj (2005) also demonstrated that enjoyment in helping others, which stems from altruism (Lin, 2007; Meier \& Stutzer, 2008), had a positive impact on an individual's knowledge-sharing behaviour. The positive psychological effects mentioned above, such as altruistic behaviour and enjoyment in helping others, have all been found to be significantly associated with an often overlooked consideration in positive psychology: an individual's greater sense of well-being (Lin, 2007; Midlarsky \& Kahana, 2007; Meier \& Stutzer, 2008). In fact, the sense of well-being has been explored and discussed more and more in western countries (Seligman \& Csikszentmihalyi, 2000). The importance of the sense of well-being can be seen in "Nicomachean Ethics", written by Aristotle in 350 BC (Johnson-Miles, 2007, p.3), where he states that "Happiness is the meaning and the purpose of life, the whole aim and end of human existence.” More importantly, Carr (2004) stated that the central concept of positive psychology consists mainly of two elements, happiness and well-being, while Lyubomirsky, 
Sheldon and Schkade (2005) pointed out that, for the majority of human beings, it is imperative to pursue sustainable happiness and a long-term sense of well-being. An increasing number of research studies have suggested that individuals who experience greater happiness and satisfaction are relatively more successful in organisations (Boehm \& Lyubomirsky, 2008). Past research has found that, not surprisingly, individuals' sense of well-being is strongly associated with income (Diener \& Biswas-Diener, 2002), helping co-workers (George, 1991), and giving social support to colleagues (Iverson, Olekalns, \& Erwin, 1998). Most research studies have speculated that such signals of achievement and success in work tasks cause an individual to be happy (Boehm \& Lyubomirsky, 2008). To date, however, no research seems to have explored empirically the relative effects of organisational culture, social capital tendency, employees' sense of well-being, and the different types of knowledge-sharing behaviour (namely tacit and explicit). Hence, the alternative hypothesis speculated by this study, that employees' sense of well-being mediates the relationship among organisational culture, social capital tendency and both employees' tacit and explicit knowledge-sharing behaviour, may be equally plausible.

This study aims to offer a more comprehensive understanding of the factors improving or prohibiting employees' knowledge-sharing behaviour within the virtual organisation of Taiwanese non-governmental organisations (NGOs). In Taiwan, non-profit organisations (NPOs), which are regarded prevalently as NGOs, are organisations that use surplus revenues to achieve their goals, instead of distributing them as profits (Jau, 2014). According to statistical data from the Department of Statistics, Ministry of the Interior, Republic of China (Taiwan), in 2013, 40,316 NGOs had been established in Taiwan. However, unlike for-profit organisations, NPOs need more to be managed more effectively (Drucker, 1990) and have the demand for continuous improvement (Lettieri, Borga, \& Savoldelli, 2004). One important factor in this regard is that NGOs often lack distinct knowledge of management and this may hinder their organisational development (Chi, Yeh, \& Yu, 2008). Liu and Fang (2010) further point out that most employees working in Taiwanese NGOs face the considerable challenges of a flat hierarchical structure, lower salaries and unclear promotion opportunities. Moreover, it is of the utmost importance to share the knowledge that exists among the members of different organisations because it is through such knowledge-sharing that organisations can increase their profile in gaining market opportunities, enhancing performance and competing in an uncertain environment (Hong et al., 2011). Hence, comprehending the factors that affect the knowledge-sharing behaviour of individuals who work within the virtual organisation of Taiwanese NGOs seems difficult to explore and yet may be regarded as being all the more valuable. Consequently, in the light of the important but elusive factors concerning knowledge sharing among individuals in such organisations, this research, based on the concept of organisational behaviour proposed by Langton, Robbins and Judge (2012), 
developed a theoretical model which integrates organisational culture (the macro-level), workplace networks (i.e. social capital tendency) (the meso-level), employees' sense of well-being (the micro-level), and their knowledge-sharing behaviour through the use of ICTs within the virtual organisation, composed of the four organisations of Taiwanese NGOs in a Chinese cultural context. This research has developed a theoretical framework in which a critically intrinsic motivation of an individual, the sense of well-being, is integrated with organisational culture and social capital tendency to explore employees' knowledge-sharing behaviour within a virtual organisation. The specific objectives of this research were to: (1) analyse the role of Information and Communication Technology (ICT) associated with employees' knowledge-sharing behaviour; (2) explore the correlation between organisational culture and employees' sense of well-being; (3) deepen the understanding of the impact of employees' social capital tendency on their sense of well-being; (4) explore the impact of employees' sense of well-being on their knowledge-sharing behaviour within the context of the virtual organisation in a Chinese cultural context.

\section{Theoretical framework and development of hypotheses}

\subsection{The concept of organisational behaviour applied in this research}

Having considered that the diverse reasons for the knowledge-sharing behaviour of an individual within the complex context of a virtual organisation are abstruse and difficult to understand in depth, this research chose to adopt the concept of organisational behaviour proposed by Langton et al. (2012) in order to deepen the investigation of those aspects that affected employees' knowledge-sharing behaviour in the selected virtual organisation. Fundamentally, organisational behaviour, which involves psychology, sociology and anthropology, can be classified into three main levels. These levels involve individuals in organisations (the micro-level), work groups in organisations (the meso-level) and organisational systems (the macro-level); they affect behaviour within an organisation in terms of applying knowledge with a view to enhancing the organisation's effectiveness (Langton et al., 2012). Based on the concept of these three distinct but related levels of organisational behaviour, the researcher explored and analysed the essential elements of employees' knowledge-sharing behaviour in the virtual organisation in terms of the three levels: namely, the macro-level (organisational culture and knowledge-sharing behaviour using ICTs), the meso-level (employees' workplace networks (i.e. social capital tendency)), and the micro-level (employees' sense of well-being). Fig. 1 depicts the concept of organisational behaviour applied in the research. 


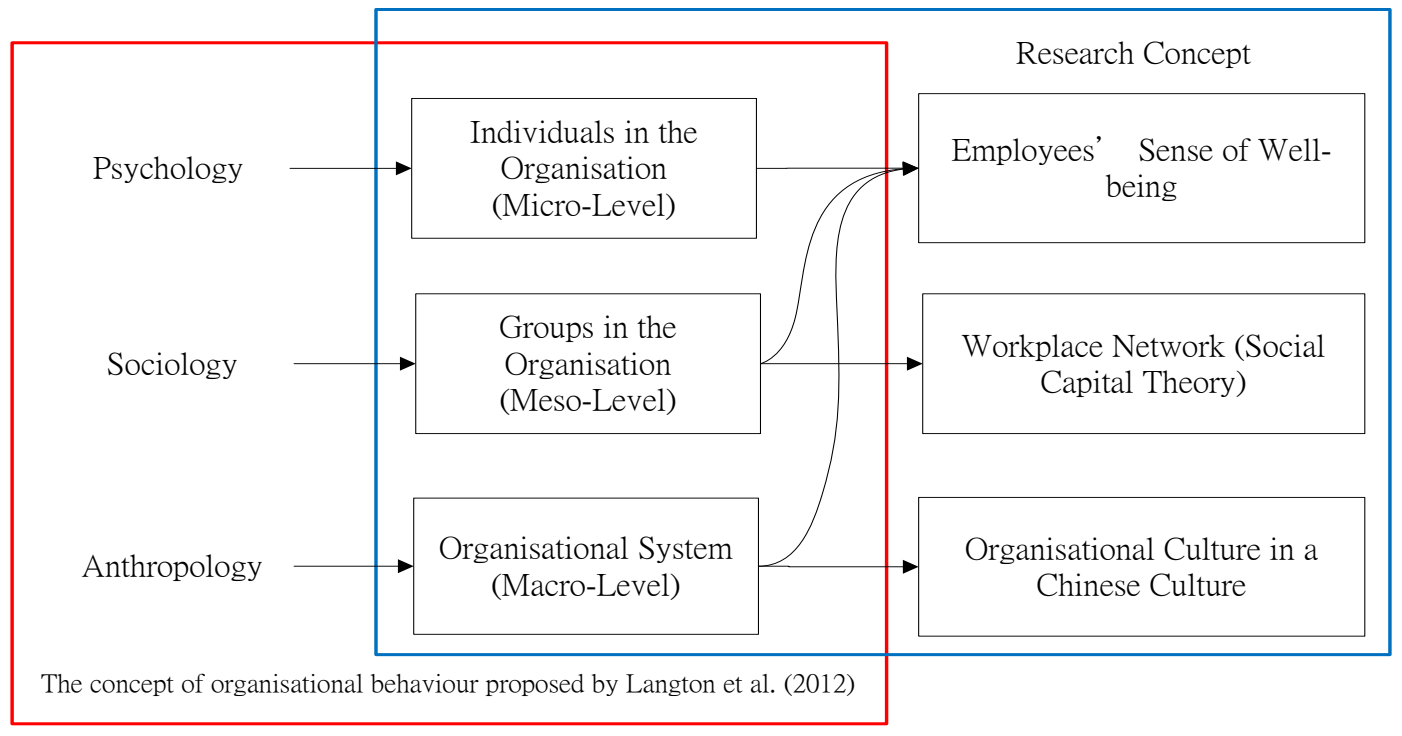

Fig. 1. The Concept of Organisational Behaviour Applied in the Research

\subsection{What makes people happy? The definition of the sense of well-being}

Happiness is the meaning and the purpose of life, the whole aim and end of human existence. - Aristotle in "Nicomachean Ethics" written in 350 BC (Johnson-Miles, 2007, p.3).

By definition, Aristotle's central thought here is that the ultimate purpose of human existence is to pursue happiness. However, over the past few decades, psychologists have paid more attention to investigating negative psychological factors when seeking to comprehend the behaviour and mental activities of individuals (Simonton \& Baumeister, 2005). More recently, though, a significant number of researchers and scholars have begun to explore positive psychological aspects as opposed to more negative ones. Positive psychology was initially proposed by Seligman and Csikszentmihalyi (2000) who focused mainly on how to make the lives of individuals more fulfilling and valuable. They also stated that positive psychology at a subjective level consists of valued subjective experiences, comprising feelings of well-being, contentment, satisfaction, hope, optimism and happiness. Another important concept of happiness suggested by Aristotle is that, for an individual, one of the most of important things is to pursue self-realisation and strive to fulfill his/her true potential. This is associated with virtue, rather than merely being part of an individual's subjective desire to feel happy (Ryff \& Singer, 2008). Later, Carr (2004) stated that the central concept of positive psychology consists mainly of two elements, happiness and well-being, while Lyubomirsky et al. (2005) pointed out that, for the majority of human beings, it is imperative to pursue sustainable happiness and a long-term sense of well-being. 
By looking at the previous reference, in recent decades, many research studies into the sense of well-being have been discussed by numerous researchers according to their different motivations, recognitions and viewpoints. These include Maslow's hierarchy of needs (1968), DeNeve and Cooper's goal-directed behaviour (1998), and Heady and Wearing's dynamic equilibrium model (1989). The hierarchy of needs proposed by Maslow (1968) suggests that the needs of human beings can be divided, as in the shape of the pyramid, into five levels with the most basic needs of individuals at the bottom and the need for self-actualisation at the peak. The lower four levels of the pyramid include physiological needs, such as the need for safety, love, belonging and esteem, highlighting that individuals may feel anxious and tense if they perceive a deficiency in these areas. In terms of the need for self-actualisation, this refers to the individual realising his/her full potential. Each lower level need should be fulfilled first, followed by needs at the higher levels (Maslow, 1968). The hierarchy of needs (Maslow, 1968), therefore, is closely related to the concept of well-being mentioned by Sheldon and Bettencourt (2002). They state that individuals will feel a sense of well-being when their needs are satisfied (Sheldon \& Bettencourt, 2002).

Recently, positive psychology with regard to well-being has been discussed a great deal in western countries, focusing in particular on senior citizens and adolescents. This growing number of researchers has gradually divided into two camps considering different yet related perspectives or factors: namely, hedonism and eudemonism (Ryan \& Deci, 2001). The psychologists who focus on hedonistic perceptions consider that personal well-being consists of subjective happiness, the attainment of pleasure and the avoidance of pain; this focus is often utilised in appraisals of subjective well-being. Eudemonic psychologists, however, view individuals' well-being as a more complex, contextual and meaningful sentiment; this is measured by an assessment of psychological well-being (Ryan \& Deci, 2001). In addition, Keyes (1998), who proposed the concept of social well-being, suggests that an individual's sense of well-being should take into account not only his/her private life, but also in his/her extrinsic social existence. Meanwhile, the job and life satisfaction of an individual overlaps and is inter-related to a large degree since an individual's job plays a critical role in his/her life and job satisfaction may spill over into life satisfaction or vice versa (Saari \& Judge, 2004). This is because an individual involved in a complex society still needs to confront a variety of social challenges. Furthermore, Keyes (1998) and Keyes, Shmotkin and Ryff (2002) indicate that an individuals' sense of well-being should be involved with subjective and psychological well-being, as well as social well-being, as these three constructs are highly related to each other. Considering a variety of instruments and the complex abstract concept of an individual's sense of well-being, the Oxford Happiness Questionnaire Short-Form (OHQ), developed by Hills and Argyle (2002) and associated with the scale for psychological 
well-being, has been adopted by this research. Chief among the reasons for this choice is that the OHQ stemmed from the Oxford Happiness Inventory (Argyle, Wiethoff, \& Klein, 1989) developed by Hills and Argyle (2002); this is widely commended for its robust construct validity and reliability (Hills \& Argyle, 2002; Robbins, Francis \& Edwards, 2010).

\subsection{Social capital tendency and employees’ sense of well-being}

As noted earlier, Aristotle, in "Nicomachean Ethics” written in 350 BC (Johnson-Miles, 2007, p.3), states that "Happiness is the meaning and the purpose of life, the whole aim and end of human existence.” An individual who experiences greater happiness and satisfaction with life seems more to be successful in his/her work tasks in an organisation (Boehm \& Lyubomirsky, 2008). It can thus be seen that an individual's sense of well-being plays a pivotal role in the meaning of his/her existence. Furthermore, Yip et al. (2007) found evidence that the social capital tendency of an individual has a positive impact on his/her psychological health and feeling of well-being. One important element, trust, which is relevant to the relational capital of social capital theory, may correspond to positive relations with others and therefore psychological well-being, as suggested by Ryff and Singer (2008), indicating that individuals have a greater sense of well-being because of their ability to put their trust in interpersonal relationships and to show loving care for others. Moreover, when it comes to the impact of cognitive capital on employees' sense of well-being, Keyes (1998) indicates that an individual's social well-being will be increased if he/she perceives to have things in common with others and recognises that they belong to part of a group. Locke and Lathem (2006) assert that when the higher personal goals of an individual are compatible with collective goals, collective performance is more effective. Helliwell and Putnam (2004) attest that social capital is strongly linked to subjective well-being through many independent channels, such as the level of network ties to friends and neighbours, the degree of civic engagement, and being trustworthy and able to trust. Consequently, in order to analyse the impact of employees' social capital tendency on their sense of well-being within the virtual organisation, this research adopted the concept of social capital mentioned by Hau, Kim, Lee and Kim (2013) who defined social capital as a second-order-formative construct comprising social ties, shared goals and social trust. This leads to hypothesis $\mathbf{H 1}$.

H1. Social capital tendency positively affects employees'sense of well-being.

\subsection{Organisational culture and employees'sense of well-being}

Over the past few decades, organisational culture has been increasingly acknowledged by researchers and practitioners because of its influence in individuals' conscious and 
subconscious thought and decision making (Lok \& Crawford, 2003), as well as its ultimate influence in improving organisational performance and maintaining a competitive edge (Khan \& Afzal, 2011; Shao, Feng, \& Liu, 2012). Camic (1986) stated that not only individuals, but also collectives, oscillate between two poles: namely, consciousness or reflection on the one hand and cultural habits on the other. As a result, the perceptions and behaviours of an individual involved with implementing knowledge management may be keenly reflected through their specific culture (Ruggles, 1998). Fundamentally, organisational culture is the shared awareness of colleagues with shared assumptions, values, beliefs and norms (Schein, 1985). Lai and Lee (2007) state that organisational culture is formed from the shared interpretations and understanding of organisational events; it develops over time. The framework of organisation culture suggested by Schein (2004) reveals that organisational culture consists mainly of three levels: artifacts; espoused beliefs and values; and underlying assumptions, (which range from very obvious and visible manifestations that can be seen and felt by members to embedded, unconscious and invisible assumptions). The level of organisational culture that resides in artifacts is a visible and perceivable phenomenon in the form of, for instance, language, myths, stories, ceremonies, rites and products. A similar artifact, however, might have a range of different meanings in different organisations (Schein, 2004). Values represent the organisation's philosophy, strategies and targets; in this regard, organisational members may have varying values at an initial stage but there will emerge a growing consensus of such values as time passes (Schein, 2004). Assumptions can be viewed as the extreme essence of an organisation's culture; they are stable and invariable and can influence members' behaviour, thoughts and perceptions (Schein, 2004). Likewise, respective organisations have unique and particular cultures which have developed over time; these reflect the characteristics of the organisation in two dimensions: visible and invisible (McDermott \& O'Dell, 2001). The visible dimension refers to the artifacts of the organisational culture, which include values, philosophy and missions, whereas the invisible dimension reflects the actions and viewpoints of employees; these are difficult to present or state (McDermott \& O’Dell, 2001). Moreover, Wallach (1983) states that organisational cultures should not be specifically divided into three categories (namely, into bureaucratic, supportive and innovative cultures). This is because the combination of traits from these three categories of organisational culture will vary from one organisation to another. Consequently, the quantitative scales of organisational culture used in this research were established with reference to Wallach's (1983) Organisational Culture Index (OCI). The primary reason for choosing Wallach's (1983) Organisational Culture Index for this research was that, although a multitude of typologies, categories and instruments for measuring organisational cultures exist, there is little agreement on which ones are superior to or more appropriate than others (Li, 2004; Lok \& Crawford, 2004; Yiing \& Ahmad, 2009). 
By way of preview, there is no denying that a great many research studies have widely demonstrated that organisational culture is regarded as a critical factor that strongly influences individuals' knowledge-sharing behaviour in organisations (Al-Alawi, Al-Marzooqi, \& Mohammed, 2007; Jo \& Joo, 2011; Suppiah \& Sandhu, 2011; Shao et al., 2012; Lee, Shiue, \& Chen; 2016). However, a link is still lacking between organisational culture and employees' sense of well-being. Basically, organisational culture has been widely viewed as the "glue" that effectively binds organisational members together by providing the cultural characteristics of cohesiveness and coherence. Furthermore, Keyes (1998) states that social coherence, based on the concept of social well-being, is the degree to which an individual understands about what is happening in the world. Hence, an individual's feeling of well-being may increase because of social coherence in these organisations. It applies to individuals who have sufficient ability to understand, feel or even predict what is happening around them (Keyes, 1998). Concerning the quantitative scales of organisational culture used in this research, these were established with reference to Wallach's (1983) Organisational Culture Index (OCI). One dimension, the bureaucratic type of organisation culture mentioned by Wallach (1983), may lead employees to feel a lower sense of well-being. A bureaucratic culture, which is based on control and power, highlights the characteristics of hierarchical management structures with clear divisions of responsibility and authority (Wallach, 1983; Cameron \& Quinn, 2006; Yiing \& Ahmad, 2009). An individual working in an organisation with a bureaucratic type may have insufficient autonomy in such a culture to the extent that his/her feeling of well-being may decrease considerably as a result of this lack of self-determinism (Ryff \& Singer, 2008). Koberg and Chusmir (1987) also found that bureaucratic culture had a significant negative impact on satisfaction and involvement and an increased propensity to leave. This may be because such organisational members have a distinct sense of authority in their highly standardised, regular, ordered, cautious and systematic ways of working (Chen, $\mathrm{Ng}, \& \mathrm{Li}, 2012$ ). As a result, employees may experience lower levels of well-being because such an organisational culture may deprive them of their sense of autonomy, self-determination and independence. Autonomy has been commonly seen as an important component of psychological well-being, as mentioned by Ryff and Keyes (1995) and Ryff and Singer (2008). Jung (1933) emphasises the importance of “individuation”, a concept which describes someone who no longer espouses collective fears and beliefs, as well as the laws of the masses. As a result, an individual's feeling of well-being may decrease considerably as a result of losing his/her autonomy. Thus, this leads to hypothesis $\mathbf{H} 2$.

H2. A bureaucratic organisational culture negatively affects employees'sense of well-being.

On the contrary, a supportive culture consists of trust, interactions, collaboration, 
encouragement and equitableness among its organisational members; this results in a more friendly and pleasant organisation (Wallach, 1983; Cameron \& Quinn, 2006; Yiing \& Ahmad, 2009). Koberg and Chusmir (1987) and Chen et al. (2012) further state that an organisation belonging to a supportive culture will provide a harmonious atmosphere in which its members can work with other colleagues. One important element of psychological well-being, namely positive relations with others, concerns the importance of warm, friendly and trusting interpersonal relationships in the environment; this may also be linked to the perspective of social well-being (Keyes, 1998). Keyes (1998) stated, for instance, that an individual who holds a socially acceptant point of view possesses a willingness to trust others, thinks that people are capable of kindness, believes that others are industrious, and feels comfortable with them. Hence, based on the above perspectives noted in numerous research studies concerning the relationship between supportive cultures and well-being, it is clear that an individual's sense of well-being is strongly associated with a supportive culture in the virtual organisation. This leads to hypothesis $\mathbf{H 3}$.

H3. A supportive organisational culture positively affects employees' sense of well-being.

Moreover, Wallach (1983) and Yiing and Ahmad (2009) state that an innovative culture has the characteristics of a creative, challenging, results-oriented and risk-taking working environment. Organisational members involved in an innovative culture are more creative and liberated; thus, they are more likely to be entrepreneurial (Koberg \& Chusmir, 1987; Chen et al., 2012). This concept is also associated with the personal growth of psychological well-being which encourages people, not only to achieve set tasks, but also continually to develop their potential (Ryff \& Singer, 2008). Likewise, social actualisation, which is one of the important elements of social well-being developed by Keyes (1998), claims that an individual who holds this point of view believes that society has the potential to achieve continual growth through its institutions and citizens. The realisation of social potential is similar to the critical dimension of personal growth in psychological well-being where people think that they can continually grow as individuals (Keyes, 1998; Ryff, 1989). As noted above, this research considers that an individual's sense of well-being is highly associated with an innovative culture in the virtual organisation. Hence, this leads to the following hypothesis.

H4. An innovative organisation culture positively affects employees'sense of well-being.

\subsection{Employees' sense of well-being and their tacit and explicit knowledge-sharing behaviour}

By looking back to previous research, in spite of the existence of the varied nature of the 
philosophical controversy with regard to exactly what knowledge is, a great many research studies concerning knowledge management (KM) have dismissed the positivistic view of knowledge as knowledge which is truly objective and the absolute truth (Stenmark, 2000). Instead, such researchers have adopted a pluralistic epistemology which acknowledges that there are many forms or types of knowledge existing in human beings (Wasko \& Faraj, 2000; Alavi \& Leidner, 2001; Joshi, Sarker, \& Sarker, 2007). For instance, Nonaka et al. (2000) clarified that the generation, process and creation of new organisational knowledge can be regarded as a spiral model involving the transfer of four modes (namely, socialisation, externalisation, combination and internalisation), moving between tacit knowledge and explicit knowledge. Even though, according to the existential literature, the different types of human knowledge have been classified in several ways, they all more or less build on the influential work of Polanyi $(1958,1966)$ concerning tacit knowledge. In his book, Polanyi states that "For just as, owing to the ultimately tacit nature of all our knowledge, we remain ever unable to say all that we know, so also, in view of the tacit character of meaning, we can never quite know what is implied in what we say” (Polanyi, 1958, p. 95). Hence, tacit knowledge appertains to highly personalised knowledge which is difficult to formalise or write down (Nonaka, 1991; Birkinshaw, 2001); it consists of mental models, beliefs, values, insights, emotions and perspectives. In contrast to tacit knowledge, explicit knowledge can be captured, codified and written in the form of technical or academic data and presented in such forms as journals, manuals, documents and patents (Nonaka \& Takeuchi, 1995; Alwis, 2008; Nonaka \& Krog, 2009). Recently, positive psychology has replaced its negative counterpart and is now taken into more consideration when seeking to comprehend the behaviour and mental activities of individuals (Simonton \& Baumeister, 2005). On the other hand, prior research on positive emotions or the psychological traits of individuals has shown that these have a positive impact on knowledge-sharing behaviour. To illustrate this, Wasko and Faraj (2005) demonstrated that positive psychological characteristics, such as delight and enjoyment in helping others, have a positive impact on individuals' knowledge-sharing behaviour. George and Brief (1992) indicated that individuals who demonstrate positive moods and traits are more likely to offer suggestions for improvements, develop their personal potential, protect the organisation, and spread goodwill to others. Similar positive characteristics, like working hard, volunteering for optional tasks, helping others and being cooperative, have a similar effect (Borman, Penner, Allen, Motowidlo, 2001). Such behaviours, as mentioned above, are highly overlapping in nature and are associated with positive emotions, thus improving the functioning of organisations. Most importantly, Carr (2004) concluded that the key central concept of positive psychology consists mainly of two elements, happiness and well-being, while Lyubomirsky et al. (2005) pointed out that, for the majority of human beings, it is imperative to pursue sustainable happiness and a long-term sense of well-being. Simultaneously, one of the most critical elements of psychological 
well-being, namely enjoying positive relations with others, is mentioned by (Ryff, 1989, p.1071) who stated that “...Self-actualizers are described as having strong feelings of empathy and affection for all human beings and as being capable of greater love, deeper friendship, and more complete identification with others..." These are consistent with the findings of Shanafelt et al. (2005) and Thomas et al. (2007) who demonstrated that individuals' sense of well-being is significantly and positively associated with empathy. Moreover, the need for empathy and concern for others is fundamental to sharing knowledge (Brown \& Woodland, 1999; Rastogi, 2000, Von Krogh, 1998). This may therefore be said to correspond to the findings of George (1991) who indicated that the happier individuals feel, the more willing they are to help fellow workers and customers (1991). Hence, by extending the concept of the sense of well-being as mentioned above, it can be seen that an individual's positive behaviour, such as helping others or sharing knowledge, may be cultivated because it increases the sense of well-being. Likewise, as noted above, this research considers that different types of knowledge (i.e. tacit and explicit) should be further distinguished and explored respectively. This leads to the following hypotheses.

H5. Employees' sense of well-being positively influences their tacit knowledge-sharing behaviour.

H6. Employees' sense of well-being positively influences their explicit knowledge-sharing behaviour.

As noted in prior references and the above-mentioned hypotheses, this research further considers that employees' sense of well-being plays an important mediating role in enhancing the relationships among social capital tendency, organisational culture and their knowledge-sharing behaviour. It leads to the following hypotheses.

H7. Employees' feeling of well-being mediates the relationship between their social capital tendency and their (tacit and explicit) knowledge-sharing behaviour in the virtual organisation.

H8. Employees' sense of well-being mediates the relationship between (bureaucratic, supportive and innovative) organisational culture and their (tacit and explicit) knowledge-sharing behaviour in the virtual organisation. 


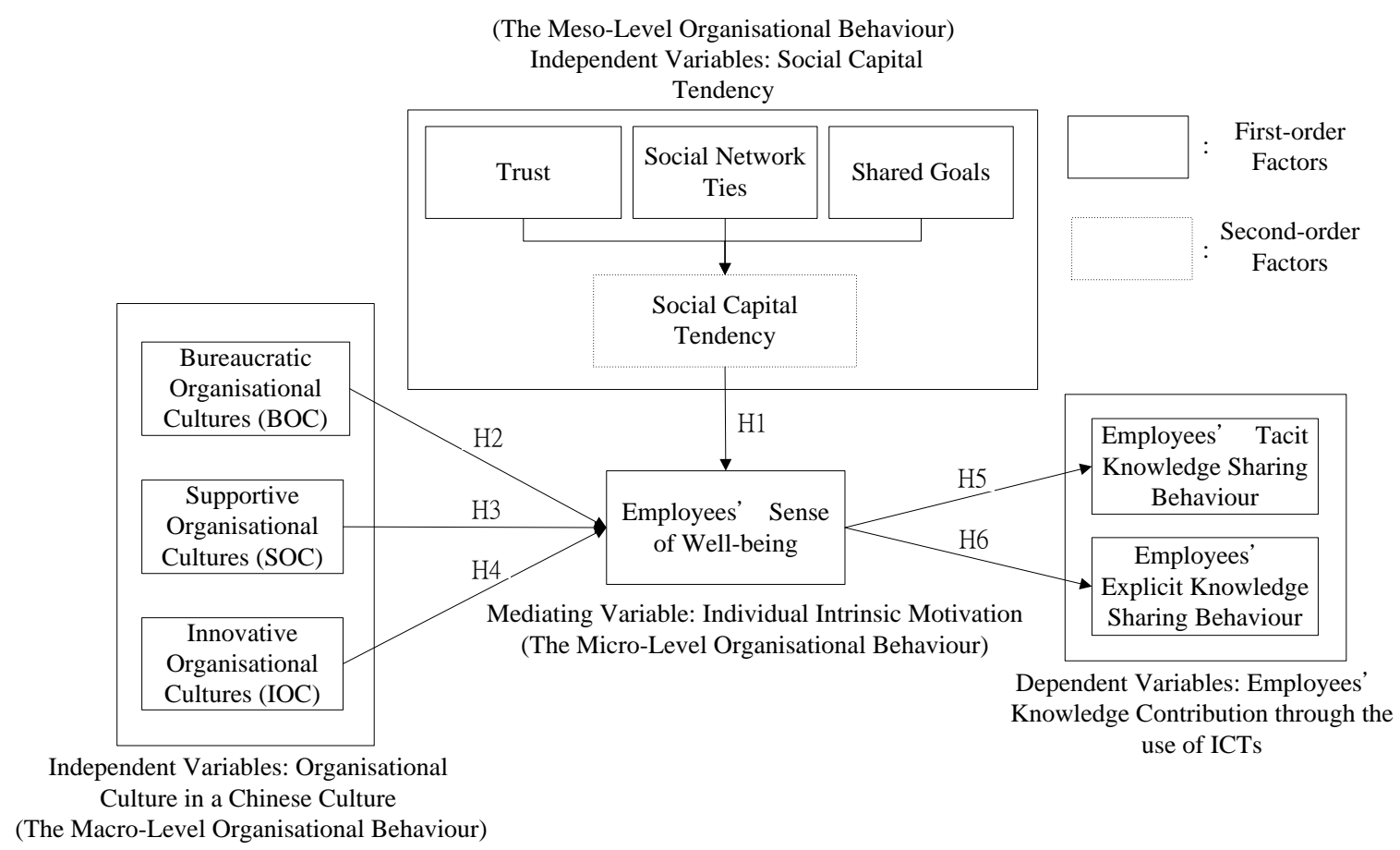

Fig. 2: The Research Model

\section{Research methodology}

\subsection{Case study background}

This research mainly investigates antecedents that may affect the knowledge-sharing behaviour of employees in the whole system of Farmers' Associations in Taiwan. The primary aim for choosing this target for the research is that the foundation and backbone of Taiwan rest with agriculture. Hence, the lifestyles of most Taiwanese citizens, with regard to their political, economic, cultural and religious activities, depend heavily on agriculture (Ding, 2011). By looking back into Taiwanese history, Taiwanese Farmers’ Associations have played a most important role in improving the economic development of the whole of Taiwanese agriculture during the past few decades (Ding, 2011). This whole system, which is regarded as a virtual organisation of NGOs in this research, is composed of three different levels of Taiwanese Farmers' Associations, plus the National Training Institute for Farmers' Organisations (NTIFO). According to Huang (1992), these three primary categories of Taiwanese Farmers' Associations (namely, urban, hybrid and rural) are largely representative of the percentage of farmers in the total working population. Hence, having considered numerous factors (i.e. the categories of Farmers' Associations (namely, urban, hybrid and rural types); the size of the sample; the possible co-operative relationships among Farmers' Associations; the narrow nature of the Taiwanese territory and the ultimate aim of this research), stratified purposive sampling was adopted to select the respondents for the 
quantitative approach of this research. As a result, respondents were selected from one urban Farmers' Association, one hybrid Farmers' Association and one rural Farmers' Association in the same administrative region, together with a sample from the NTIFO. Moreover, this research defines a virtual organisation as one consisting of a number of dynamic and temporary companies whose employees work cooperatively and coordinate flexibly to pool their facilities and infrastructures. Employees also share skills, competencies, knowledge and resources by using Information and Communication Technologies (ICTs), such as Knowledge Management Systems (KMS) and video conferencing, with a view to pursuing a particular goal or better market opportunity (Goldman, Nagel, \& Preiss, 1995; Squicciarini et al., 2011). Definitions of the virtual organisation offered by a number of scholars are integrated in Appendix B.

\subsection{Quantitative instrument development}

Having considered the aim and objectives of the research, stratified purposive sampling was utilised to select the respondents. A questionnaire in English was devised using measures (referred to previously) which showed robust reliability and validity. All items of the questionnaire were measured using a 5-point Likert scale, ranging from 1 = strongly disagree to 5 = strongly agree. Meanwhile, two senior supervisors from Loughborough University, all of whom had relevant expertise in the relevant knowledge management and industrial domains, were also invited to appraise the questionnaire in terms of its appropriateness and ease of comprehension in order to strengthen the instrument's validity. Several items of the questionnaire were then adjusted because the professors considered that the wording and phrasing of these items were too academic or difficult for respondents to read, while two items associated with organisational culture were removed because of their sensitivity. After this screening procedure, the final version of the pilot questionnaire contained 34 items. Then, a pilot study was conducted, initially to evaluate the validity and reliability of the content of the questionnaire used in this research. Finally, 43 valid questionnaires were returned from the pilot via e-mail from the selected virtual organisation. The measurement model was then evaluated, using Smart-PLS (Version: 2.0.M3), in order to analyse the survey's reliability (both individual item reliability and internal consistency) and validity (i.e. convergent validity and discriminant validity). The analytic results showed solid individual item reliability, internal consistency and validity.

\subsection{Data collection}

Consequently, the full-scale questionnaire was distributed among the respondents who all worked in the Association's affairs, accounting, extension, marketing, credit and insurance 
departments; in farmers' services; in a product market processing plant; and at an information office in the chosen virtual organisation. Finally, a total of 131 valid paper questionnaires, from 56 males and 75 females in the virtual organisation composed of three different levels of Farmers' Associations in the same administrative region and NTIFO, were collected during the period from April 2014 to August 2014. Table 1 represents the relevant characteristics of the respondents of this research.

\section{Table 1}

Demographic Profile of the Respondents

\begin{tabular}{|c|c|c|c|}
\hline Variables & Categories & N/WF & $\%$ \\
\hline \multirow[t]{4}{*}{ Information re. the Virtual Organisation } & Company 1 (NTIFO) & $36 / 57$ & 27.4 \\
\hline & Company 2 (Urban FA) & $30 / 56$ & 23.0 \\
\hline & Company 3 (Hybrid FA) & $31 / 55$ & 23.7 \\
\hline & Company 4 (Rural FA) & $34 / 56$ & 25.9 \\
\hline \multirow[t]{2}{*}{ Gender } & Male & 56 & 42.7 \\
\hline & Female & 75 & 57.3 \\
\hline \multirow[t]{7}{*}{ Age } & 21 25 Years Old & 7 & 5.3 \\
\hline & 26 30 Years Old & 10 & 7.6 \\
\hline & 31 35 Years Old & 18 & 13.7 \\
\hline & 36 40 Years Old & 12 & 9.2 \\
\hline & 41 45 Years Old & 23 & 17.6 \\
\hline & 46 50 Years Old & 20 & 15.3 \\
\hline & 51 Years Old (Over) & 41 & 31.3 \\
\hline \multirow[t]{7}{*}{ Working Years } & 1 Year (Under) & 11 & 8.4 \\
\hline & 1 3 Years & 17 & 13.0 \\
\hline & 4 6 Years & 6 & 5.6 \\
\hline & 7 9 Years & 5 & 3.8 \\
\hline & 10 15 Years & 11 & 8.4 \\
\hline & 16 20 Years & 22 & 16.8 \\
\hline & 20 Years and Over & 59 & 45.0 \\
\hline
\end{tabular}

Note 1. FA = Farmers' Association, NTIFO = National Training Institute for Farmers' Organisations, WF = Current Work Force

\section{Data analysis and results}

\subsection{Common method variance (CMV)}

To confirm the quality of the questionnaire and to avoid the possibility of common method 
variance (bias), owing to the fact that the collected data derived from a single source, a number of methods recommended by Podsakoff, MacKenzie, Lee and Podsakoff (2003) were adopted in this research. The questionnaire was designed and administered carefully: positive and negative items were included, the respondents' anonymity was maintained, the name of each research variable was hidden, and respondents were requested to answer the questionnaire honestly. Besides this, the research used Harman's single-factor test to scrutinise the questionnaire items for CMV. The results revealed that the first factor accounted for $44.3 \%$ of the total variance. (The CMV can be treated as non-existent if the percentage of the first factor of the total variance is less than 50\% (Podsakoff \& Organ, 1986)). This implies that no single factor accounted for the majority of the variance and therefore common method variance was not likely to be a significant threat in this research.

\subsection{Procedure for the analysis of the quantitative approach}

Structural Equation Modeling (SEM), using partial least squares (PLS) with Smart PLS (Version: 2.0.M3) established by Ringle, Wende and Will (2005), was chosen to analyse the proposed hypotheses of this research. PLS is one of the analytic tools of Structural Equation Modeling (SEM). It is well-designed statistical analytic software for evaluating complicated predictive and multivariate models, including analysis of both the measurement and structural models (Chin, 1998a; Joreskog \& Wold, 1982; Gefen, Rigdon, \& Straub, 2011). PLS has been widely used in IS research, such as in the work of Wasko and Faraj (2005) and Shao et al. (2012), on account of its ability to analyse both reflective and formative constructs, and to deal with smaller sample sizes without the need to normalise the data (Chin et al., 2003).

\subsection{Measurement model}

The evaluation of the measurement model consisted mainly of two main aspects, including tests of the reliability and validity of the instrument items. The reliability test of the measurement model included assessing the reliability of each item of the instrument and estimating internal consistency by using Cronbach's Alpha and composite reliability. The test of the validity of the measurement model evaluated both the convergent and discriminant validity of the instrument items by utilising Average Variance Extracted (AVE) and the square root of the Average Variance Extracted (AVE) (Wixom \& Watson, 2001; Chin et al., 2003). The results of the analysis revealed that the factor loading values for most items were greater than 0.7 and so were significant, except for WB1 and BOC1 which had lower factor loading values of 0.65 and 0.67 respectively. These items (WB1 and BOC1) were therefore dropped from the measurement model which was then retested. The analytic results then showed a greater value of factor loading for each item (see Table 1 and Appendix A). Barclay, 
Thompson and Higgins (1995) indicated that, when the factor loading value of each item is virtually at or greater than 0.7 , it can be deemed to have individual item reliability. With regard to the Cronbach Alpha values of each construct evaluated in this research, the values of all constructs were higher than 0.7, ranging in fact from 0.775 to 0.937 . Robinson and Shaver (1973) and Nunnally (1978) pointed out that each construct can be considered to have sufficient reliability when its Cronbach Alpha value is higher than 0.7. In this regard, the composite reliability (CR) measures were above 0.874 for all constructs, thus achieving an acceptable level of internal consistency (Chin, 1998b; Chin et al., 2003). Subsequently, when assessing the research's convergent validity, which was achieved by checking the Average Variance Extracted (AVE), each construct was found to have exceeded 0.5, ranging in fact from 0.613 to 0.842 . The convergent validity of each construct is deemed acceptable when the AVE value of the research constructs is above 0.5 (Fornell \& Larcker, 1981). Table 2 presents the relevant values of the measurement model, as well as descriptive statistics of the measures (mean, standard deviation, skewness and kurtosis). Meanwhile, the values of skewness and kurtosis are acceptable if their values are less than 2.0 and 7.0 respectively (Curran, West \& Finch, 1996).

\section{Table 2}

The Relevant Analytic Values of the Measurement Model of the Research (all items are listed in Appendix A)

\begin{tabular}{|c|c|c|c|c|c|c|}
\hline Constructs & Items & Mean (SD) & Loadings & t-Value & Skewness & Kurtosis \\
\hline The Sense of Well-being & WB2 & $3.01(0.91)$ & $0.700 * * *$ & 13.5 & -0.41 & -0.29 \\
\hline (Cronbach’s Alpha=0.894, & WB3 & $3.73(0.92)$ & $0.795 * * *$ & 23.3 & -0.12 & -0.73 \\
\hline \multirow[t]{5}{*}{$\mathrm{CR}=0.917, \mathrm{AVE}=0.613)$} & WB4 & $3.77(0.81)$ & $0.831^{* * *}$ & 27.6 & -0.49 & -0.06 \\
\hline & WB5 & $3.66(0.80)$ & $0.780 * * *$ & 18.2 & -0.34 & -0.42 \\
\hline & WB6 & $3.86(0.83)$ & $0.822^{* * *}$ & 25.1 & -0.26 & -0.75 \\
\hline & WB7 & $3.86(0.87)$ & $0.804 * * *$ & 24.7 & 0.16 & -0.57 \\
\hline & WB8 & $3.42(0.85)$ & $0.749 * * *$ & 16.5 & 0.25 & -0.46 \\
\hline Trust (Relational Capital ) & RC1 & $3.62(0.96)$ & $0.865 * * *$ & 40.4 & -0.43 & -0.77 \\
\hline (Cronbach’s Alpha=0.846, & $\mathrm{RC} 2$ & $3.85(0.83)$ & $0.900 * * *$ & 42.6 & -0.18 & -0.42 \\
\hline $\mathrm{CR}=0.907, \mathrm{AVE}=0.765)$ & RC3 & $3.78(0.79)$ & $0.857 * * *$ & 29.3 & 0.36 & -0.70 \\
\hline Social Network Ties (Structural & SC1 & $3.90(0.72)$ & $0.931^{* * *}$ & 66.7 & -0.08 & -0.50 \\
\hline Capital ) (Cronbach’s & SC2 & $3.88(0.72)$ & $0.943 * * *$ & 98.8 & -0.26 & -0.63 \\
\hline Alpha $=0.896, \quad$ CR $=0.935$ & SC3 & 3.64(0.89) & $0.855^{* * *}$ & 23.0 & -0.12 & -0.68 \\
\hline \multicolumn{7}{|l|}{$\mathrm{AVE}=0.829)$} \\
\hline Shared Goals (Cognitive Capital) & CC1 & $3.46(0.88)$ & $0.818^{* * *}$ & 27.5 & -0.13 & -0.27 \\
\hline (Cronbach’s Alpha=0.784, & CC2 & $3.22(0.90)$ & $0.858 * * *$ & 26.2 & 0.10 & -0.01 \\
\hline $\mathrm{CR}=0.874, \mathrm{AVE}=0.698)$ & CC3 & $3.27(0.87)$ & $0.831^{* * *}$ & 13.3 & -0.36 & -0.55 \\
\hline Bureaucratic Organisational & BOC2 & $3.82(0.74)$ & $0.777 * * *$ & 6.27 & -0.25 & -0.71 \\
\hline
\end{tabular}




\begin{tabular}{|c|c|c|c|c|c|c|}
\hline Culture (Cronbach’s Alpha=0.775, & BOC3 & 3.78(0.89) & $0.979 * * *$ & 19.4 & -0.06 & -1.15 \\
\hline \multicolumn{7}{|l|}{$\mathrm{CR}=0.875, \mathrm{AVE}=0.780)$} \\
\hline Supportive Organisational Culture & SOC1 & $3.30(1.00)$ & $0.882^{* * *}$ & 33.8 & -0.86 & 0.51 \\
\hline (Cronbach’s Alpha=0.833, & SOC2 & $3.55(0.96)$ & $0.854 * * *$ & 26.1 & -0.36 & -0.15 \\
\hline $\mathrm{CR}=0.899, \mathrm{AVE}=0.748)$ & SOC3 & $3.60(0.92)$ & $0.858 * * *$ & 28.3 & 0.22 & -0.47 \\
\hline Innovative Organisational Culture & IOC1 & 3.33(1.05) & $0.952^{* * *}$ & 88.1 & 0.18 & -0.73 \\
\hline (Cronbach’s Alpha =0.933, & IOC2 & $3.50(1.02)$ & $0.957 * * *$ & 112 & 0.11 & -1.03 \\
\hline $\mathrm{CR}=0.957, \mathrm{AVE}=0.883)$ & IOC3 & $3.48(0.99)$ & $0.909 * * *$ & 40.6 & -0.13 & -0.21 \\
\hline Tacit Knowledge Sharing & TKS1 & $3.29(0.81)$ & $0.929 * * *$ & 84.4 & 0.10 & -0.54 \\
\hline (Cronbach’s Alpha=0.937, & TKS2 & $3.59(0.83)$ & $0.910^{* * *}$ & 42.1 & -0.16 & -0.74 \\
\hline \multirow[t]{2}{*}{$\mathrm{CR}=0.955, \mathrm{AVE}=0.842)$} & TKS3 & $3.28(0.89)$ & $0.904 * * *$ & 45.0 & 0.22 & -0.42 \\
\hline & TKS4 & $3.50(0.87)$ & $0.930 * * *$ & 53.2 & -0.01 & -0.26 \\
\hline Explicit Knowledge Sharing & EKS1 & $3.68(0.97)$ & $0.892 * * *$ & 72.5 & -0.01 & -0.76 \\
\hline (Cronbach’s Alpha=0.928, & EKS2 & $3.72(0.92)$ & $0.845^{* * *}$ & 59.8 & 0.06 & -0.93 \\
\hline \multirow[t]{2}{*}{$\mathrm{CR}=0.949, \mathrm{AVE}=0.823)$} & EKS3 & $3.39(0.89)$ & $0.882^{* * *}$ & 65.8 & 0.20 & -0.77 \\
\hline & EKS4 & $3.41(0.86)$ & $0.878 * * *$ & 34.9 & 0.24 & -0.82 \\
\hline
\end{tabular}

Note 1. Items (WB1 and BOC1) were removed from the instrument because of their lower value of factor loading.

Note 2. AVE=Average Variance Extracted, $\mathrm{SD}=$ Standard Deviation, $\mathrm{CR}=$ Composite Reliability, WB=The Sense of Well-being, BOC=Bureaucratic Organisational Culture, SOC=Supportive Organisational Culture, IOC=Innovative Organisational Culture, $\mathrm{RC}=$ Trust (Relational Capital), SC= Social Network Ties (Structural Capital), CC= Shared Goals (Cognitive Capital), EKS=Explicit Knowledge Sharing, TKS=Tacit Knowledge Sharing.

Note 3: ${ }^{*} \mathrm{p}<0.05 ; * * \mathrm{p}<0.01 ; * * * \mathrm{p}<0.001$.

Discriminant validity refers to the degree to which the items distinguish between the constructs. This is estimated by two criteria: namely, the square root of the Average Variance Extracted (AVE) and cross loading. Table 3 below shows that the discriminant validity of the constructs was proved. This is because the value of the square root of the AVE of each latent variable was greater than the correlation of that construct with other constructs (Fornell \& Larcker, 1981; Chin et al., 2003). In addition, with regard to cross loading, the values of the items of each construct (shown in Appendix C) were higher than the values of the items of other constructs; these were therefore acceptable (Fornell \& Larcker, 1981; Chin et al., 2003). As noted above, the analytic results showed that the discriminant validity in this research was strong and the analytic results of the measurement model showed good reliability and validity.

\section{Table 3}


The Value of the Square Root of the Average Variance Extracted (AVE) of the Individual Latent Construct

\begin{tabular}{|c|c|c|c|c|c|c|c|c|c|c|c|}
\hline & Items & Mean/SD & BOC & $\mathrm{CC}$ & EKS & IOC & $\mathrm{RC}$ & SC & SOC & TKS & WB \\
\hline BOC & 2 & $3.80(0.74)$ & 0.883 & & & & & & & & \\
\hline CC & 3 & $3.32(0.74)$ & 0.390 & 0.835 & & & & & & & \\
\hline EKS & 4 & $3.61(0.80)$ & 0.404 & 0.447 & 0.907 & & & & & & \\
\hline IOC & 3 & $3.63(0.81)$ & 0.592 & 0.417 & 0.487 & 0.939 & & & & & \\
\hline $\mathrm{RC}$ & 3 & $3.75(0.75)$ & 0.467 & 0.680 & 0.533 & 0.545 & 0.874 & & & & \\
\hline SC & 3 & $3.81(0.71)$ & 0.292 & 0.592 & 0.566 & 0.422 & 0.652 & 0.910 & & & \\
\hline SOC & 3 & $3.48(0.83)$ & 0.520 & 0.419 & 0.491 & 0.706 & 0.588 & 0.444 & 0.864 & & \\
\hline TKS & 4 & $3.39(0.86)$ & 0.370 & 0.414 & 0.837 & 0.465 & 0.492 & 0.544 & 0.411 & 0.917 & \\
\hline WB & 7 & $3.61(0.68)$ & 0.322 & 0.681 & 0.555 & 0.485 & 0.696 & 0.641 & 0.482 & 0.489 & 0.782 \\
\hline
\end{tabular}

Note 1: Diagonal bold letters are the square roots of AVE.

\subsection{The structural model}

With the measurement model sufficiently validated, the bootstrapping technique with 500 resamples, as recommended by Chin (1998b), was used for structural measurement analysis to evaluate the path coefficients, their significance levels and the R-square $\left(R^{2}\right)$ value. Path coefficients explain the impact of each research variable on the correlations. These significance levels show whether or not all the hypotheses have a significant influence so that the theoretical model of the research can be established. The $\mathrm{R}^{2}$ value offers an explanation of variance and suggests to what percentage the exogenous variables can account for the endogenous ones; this represents the predictive ability of the research model.

\subsubsection{The structural model without considering social capital tendency}

Meanwhile, because of the lack of sufficient convincing evidence regarding the impact of organisational culture on individuals' knowledge-sharing behaviour within the context of the virtual organisation in a Chinese cultural context, and to offer a more comprehensive understanding of the mediating impact of employees' sense of well-being on organisational culture and knowledge-sharing behaviour within the virtual organisation, this study initially tested the mediating effect of employees' sense of well-being on the relationship between organisational culture and employees' knowledge-sharing behaviour without considering the social capital tendency factor. First, the study tested the model (see Fig. 3) without considering social capital tendency. The results showed that organisational culture (e.g. the supportive $(\beta=0.28 ; \mathrm{t}=2.65)$ and innovative $(\beta=0.29 ; \mathrm{t}=2.59)$ types) positively affected employees' sense of well-being which, in turn, influenced employees' tacit knowledge-sharing behaviour ( $\beta=0.54 ; \mathrm{t}=9.89$ ) and employees' explicit knowledge-sharing 
behaviour ( $\beta=0.49 ; \mathrm{t}=6.23$ ) within the virtual organisation.

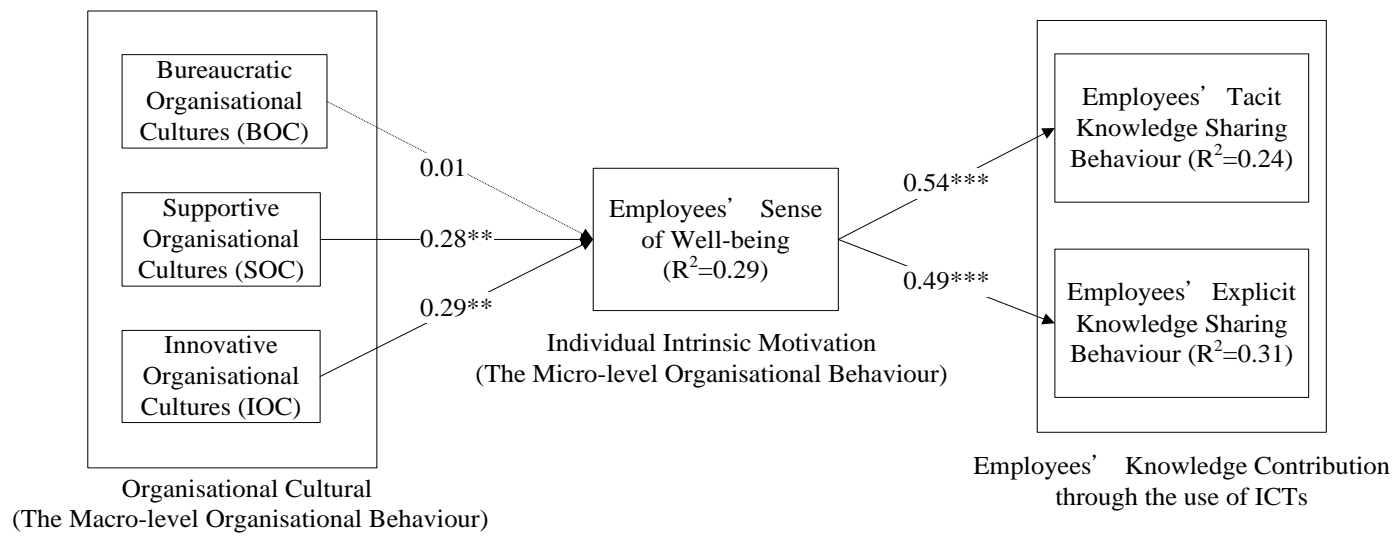

Fig. 3: PLS Analysis of Direct Effects (without considering social capital tendency)

Note 1: ${ }^{*} \mathrm{p}$-value $<0.05(\mathrm{t}>1.96) ; * * \mathrm{p}$-value $<0.01(\mathrm{t}>2.58) ; * * * \mathrm{p}$-value $<0.001(\mathrm{t}>3.29)$

\subsubsection{The overall model of the structural model}

The overall model of the structural model results are shown in Fig. 4. Social capital tendency positively affected employees' sense of well-being ( $\beta=0.72 ; t=11.70)$ thus providing support for H1. Analysis revealed that, contrary to our expectation, organisational culture (e.g. the bureaucratic, supportive and innovative types) had no significant positive impact on employees' sense of well-being. As shown in Fig. 4 below, the findings revealed that the path coefficient between the bureaucratic organisational culture and employees' sense of well-being was -0.09 which was insignificant. Therefore, $\mathbf{H 2}$ was not supported. The path coefficient between the supportive organisational culture and employees' sense of well-being was 0.03; this was insignificant and thus did not provide support for $\mathbf{H 3}$. The result of the path coefficient between the innovative organisational culture and employees' sense of well-being was 0.13 , which was also insignificant. Thus, $\mathbf{H} 4$ was not supported. Consistent with our expectation, employees' sense of well-being was strongly positively associated with their tacit knowledge-sharing behaviour $(\beta=0.48 ; \mathrm{t}=11.68)$ and their explicit knowledge-sharing behaviour ( $\beta=0.56 ; \mathrm{t}=10.72$ ). These results therefore supported $\mathbf{H 5}$ and H6. Fig. 4 below shows the results of the $R^{2}$ for the endogenous variables, the path coefficients and their significance. 


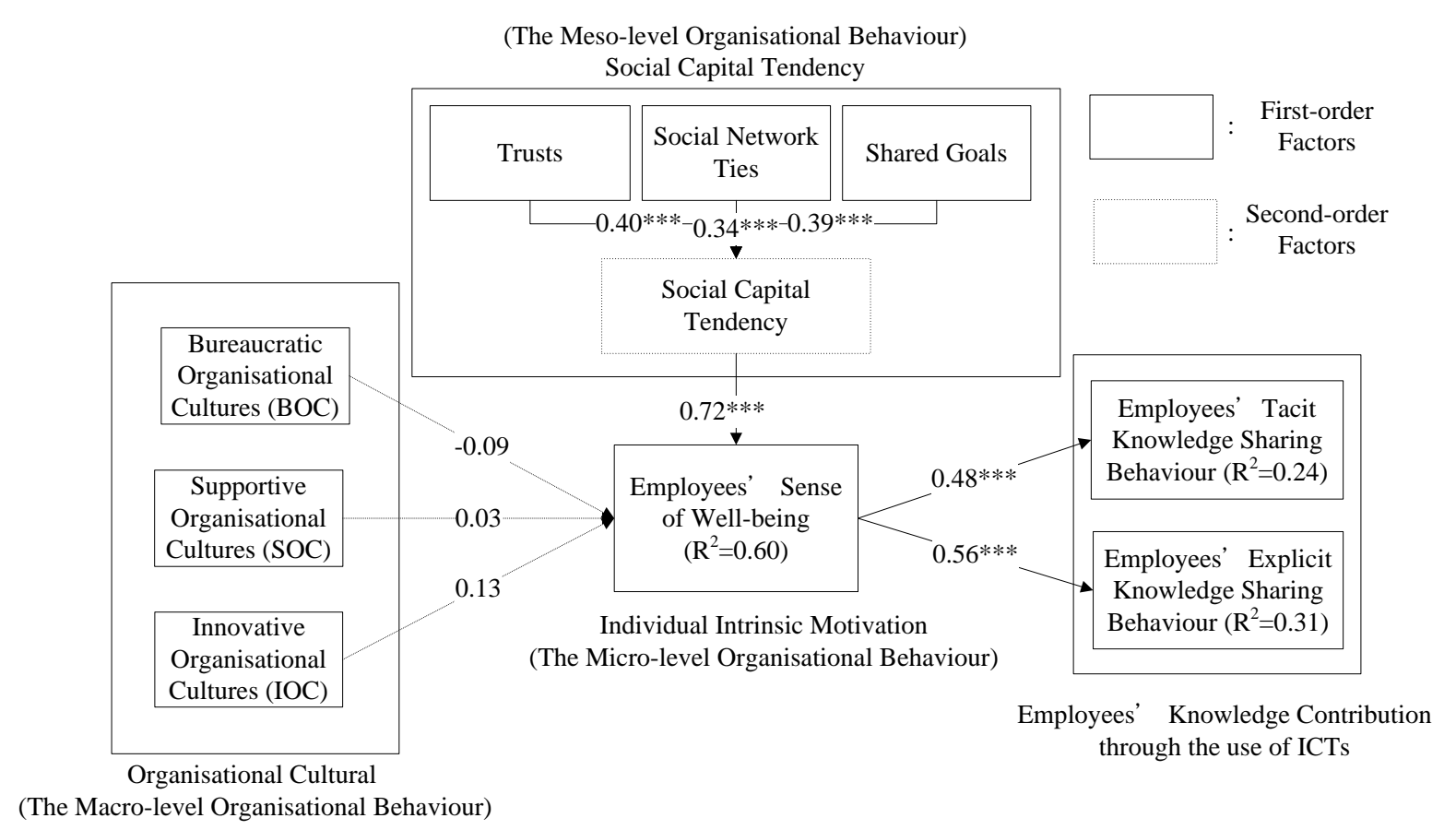

Fig. 4. PLS Analysis of Direct Effects

Note 1: *p-value $<0.05(\mathrm{t}>1.96) ;{ }^{* *} \mathrm{p}$-value $<0.01(\mathrm{t}>2.58) ;{ }^{* * *} \mathrm{p}$-value $<0.001(\mathrm{t}>3.29)$

Meanwhile, $60 \%$ of the variance in employees' sense of well-being was explained while $24 \%$ of the variance in their tacit knowledge-sharing behaviour was explained. Moreover, it can be seen that $31 \%$ of the variance in employees' explicit knowledge-sharing behaviour was explained.

\subsection{The sense of well-being as a mediating effect}

Besides, in order to comprehend in depth the mediating effect of employees' sense of well-being on the relationships between organisational culture and employees' knowledge-sharing behaviour in the virtual organisation, this research chose to adopt a three-step method for its analysis, as mentioned by Baron and Kenny (1986). As noted in Table 4, employees' sense of well-being had a positively partial mediating impact on the relationship between employees' social capital tendency and both their tacit and explicit knowledge-sharing behaviour which provides support for $\mathbf{H} \mathbf{7}$. With regard to the impact of the mediating effect of individuals' sense of well-being on the relationship between organisational culture (i.e. bureaucratic, supportive and innovative types) and both employees' tacit and explicit knowledge-sharing behaviour, the results also showed a positively partial mediating effect. Therefore, these findings provide support for $\mathbf{H} \mathbf{8}$. Moreover, Table 5 provides comparisons of the hypothesised fully mediating, non-mediating and partial mediating models. The results of the comparisons suggested that the proposed 
hypotheses of this research were accepted.

\section{Table 4}

Results of Testing for the Mediating Effect

\begin{tabular}{llllllll}
\hline \multicolumn{2}{l}{ Coefficient in Regressions } & & & \\
\hline IV & M & DV & IV $\rightarrow$ DV & IV $\rightarrow$ M & \multicolumn{2}{l}{ IV+M $\rightarrow$ DV } & Mediating \\
\cline { 6 - 8 } & & & & & IV $\rightarrow$ DV & M $\rightarrow$ DV & \\
\hline SOC & WB & EKS & $0.514^{* * *}$ & $0.450^{* * *}$ & $0.363^{* * *}$ & $0.337^{* * *}$ & Partial \\
IOC & WB & EKS & $0.506^{* * *}$ & $0.439^{* * *}$ & $0.358^{* * *}$ & $0.345^{* * *}$ & Partial \\
BOC & WB & EKS & $0.393^{* * *}$ & $0.341^{* * *}$ & $0.253^{* *}$ & $0.485^{* * *}$ & Partial \\
SOC & WB & TKS & $0.434^{* * *}$ & $0.450^{* * *}$ & $0.300^{* * *}$ & $0.303^{* * *}$ & Partial \\
IOC & WB & TKS & $0.488^{* * *}$ & $0.439^{* * *}$ & $0.366^{* * *}$ & $0.277^{* * *}$ & Partial \\
BOC & WB & TKS & $0.374^{* * *}$ & $0.341^{* * *}$ & $0.240^{* *}$ & $0.424^{* * *}$ & Partial \\
SCT & WB & EKS & $0.600^{* * *}$ & $0.772^{* * *}$ & $0.418^{* * *}$ & $0.237^{* *}$ & Partial \\
SCT & WB & TKS & $0.562^{* * *}$ & $0.772^{* * *}$ & $0.447^{* * *}$ & $0.200^{*}$ & Partial \\
\hline
\end{tabular}

Note 1: ${ }^{*}$ p-value $<0.05 ;{ }^{* *}$ p-value $<0.01 ; * * *$ p-value $<0.001$.

Note 2: IV=Independent Variable, $M=$ Mediator, $D V=$ Dependent Variable, $W B=T$ The Sense of Well-being, SOC=Supportive Organisational Culture, IOC=Innovative Organisational Culture, EKS=Explicit Knowledge Sharing, TKS=Tacit Knowledge Sharing.

Note 3: Three-step method for estimating mediating effects, suggested by Baron and Kenny (1986).

The process of testing mediating effects is organised as follows:

Step 1: IV $\rightarrow$ DV is significant.

Step 2: IV $\rightarrow \mathrm{M}$ is significant.

Step 3: IV+M $\rightarrow$ DV

1) When $M$ is significant but IV is not significant, $M$ has a full mediating effect.

2) When both $M$ and IV are significant, $M$ has a partial mediating effect.

Table 5

Results of SEM Analysis

\begin{tabular}{llcllc}
\hline \multicolumn{4}{l}{ Hypothesised Model } & \multicolumn{4}{l}{ Non-mediating Model } \\
\hline Path from & Path to & Path coefficient & Path from & Path to & Path coefficient \\
BOC & WB & -0.090 & BOC & TKS & 0.126 \\
SOC & WB & 0.034 & SOC & TKS & 0.136 \\
IOC & WB & 0.130 & IOC & TKS & $0.308^{*}$ \\
SCT & WB & $0.722^{* * *}$ & BOC & EKS & 0.138 \\
WB & TKS & $0.489^{* * *}$ & SOC & EKS & $0.273^{*}$ \\
WB & EKS & $0.556^{* *}$ & IOC & EKS & 0.271
\end{tabular}

Partially Mediating Model (without considering Social Capital tendency) 


\begin{tabular}{lll} 
BOC & WB & 0.010 \\
SOC & WB & $0.278^{* *}$ \\
IOC & WB & $0.289 * *$ \\
WB & TKS & $0.491 * * *$ \\
WB & EKS & $0.558 * * *$ \\
\hline
\end{tabular}

Note 1: ${ }^{*}$-value $<0.05 ;{ }^{* *}$ p-value $<0.01 ; * * *$ p-value $<0.001$.

\subsection{Independent-sample t test and one-way ANOVA}

Having considered that sex, age and working experience may influence knowledge-sharing behaviour (Miller \& Karakowsky, 2005; Moordian, Renzl, \& Matzler, 2006; Watson \& Hewett, 2006; Lin, 2007a, Lin, 2007b), and in order to understand in depth whether the employees from these companies within the virtual organisation had different perceptions in each construct of the research, an independent-sample t test and the one-way ANOVA test, together with the Scheffe post hoc test, were used to compare differences in terms of four categories: employees of the four different companies of the virtual organisation, the different gender and ages of employees, and employees' working year. Firstly, to understand the impact of the gender of the virtual organisation's employees on each construct of the research, an independent-sample $t$ test was conducted as part of the quantitative approach of this research. The analytic results show no significant statistical difference with regard to each construct of this research in terms of gender. Moreover, the analytic results in this study showed that the mean of employees' sense of well-being for company 4 (Rural Farmers' Association) was relatively higher (with a mean of 3.72) than that of company 1 (with a mean of 3.26) (NTIFO). This may imply that, even though employees worked together in the virtual organisation, they still had significantly different feelings about well-being because they came from the mixed cultural environment of the virtual organisation. Secondly, concerning the different ages of employees, the results showed that employees aged 46-50 (with a mean of 3.68), compared to employees aged 26-30 (with a mean of 2.98), had a greater willingness to share their explicit and tacit knowledge in the virtual organisation. These are similar to the findings of the research carried out by Strauss and Howe (1993) which showed that young employees seem more inclined to be individualistic and distrust others as compared with older/senior employees. Finally, no statistical difference was found for any of the constructs with regard to employees with different working years.

\section{Discussion and implications}

\subsection{Theoretical implications}


Even though research on motivations of an individual's knowledge-sharing behaviour has been widely explored in terms of various personal motivational factors with the one-dimensional level of organisational behaviour, it is extremely difficult to understand comprehensively individuals' knowledge-sharing behaviour within the real context of the organisation, especially a virtual organisation in a Chinese culture. This study contributes to knowledge management, particularly in terms of knowledge-sharing behaviour, in four areas. First, in the light of the lack of prior relevant research, the theoretical model built by this study, which was based on the concept of organisational behaviour proposed by Langton et al. (2012), provides a more comprehensive understanding of the effect of employees' feeling of well-being (the micro-level) on the complex relationships among organisational culture in a Chinese cultural context (the macro-level), social capital tendency (the meso-level), and employees' knowledge-sharing behaviour through the use of ICTs within a more complex context of a virtual organisation. Likewise, no previous research seems to have examined how organisational culture and workplace networks are closely intertwined and associated with individuals' sense of well-being; these, in turn, affect their knowledge-sharing behaviour within the virtual organisation. Hence, this pioneering model adds to the existing body of knowledge management concerning employees' knowledge-sharing behaviour in an organisation, especially a virtual one.

The second contribution of this research is to offer a first step towards establishing an understanding of the link between organisational culture and employees' knowledge-sharing behaviour within the virtual organisation of Taiwanese NGOs in a Chinese cultural context. Even though theories concerning organisational culture have been widely used to explore the phenomenon of social behaviour, such as individuals' knowledge-sharing behaviour and organisational performance, no research seems to have been conducted into the specific relationship between organisational cultures and employees' knowledge-sharing behaviour by considering the sense of well-being as a critical mediator in a virtual organisation. The quantitative statistical results showed that the culture of the virtual organisation seems to be a mixture of a bureaucratic (with a mean of 3.80), supportive (with a mean of 3.48) and innovative (with a mean of 3.63) types (see Table 3). The traits of such an organisational culture of the selected virtual organisation may correspond to traditional Chinese cultural features and Confucian thought, highlighting the management style of a bureaucratic culture. In fact, there is no denying that the construct of the social fabric of Chinese culture relies mainly on the Confucian (from around 551-499 BC) value system (Tong \& Mitra, 2009). Park and Luo (2001, p.456) state that "Confucianism attempts to establish harmony in a complex society of contentious human beings through a strong and orderly hierarchy.” Hence, employees who work for such an organisation in a Chinese culture may sacrifice their partial autonomy in order to pursue the ultimate targets of the organisation. The mixed 
organisational cultural characteristics may therefore constitute the source of employees' happiness and harmony within the virtual organisation of Taiwanese NGOs in a Chinese cultural context. The results also showed that features of the supportive and innovative cultures, such as support from colleagues and bosses, harmonious interpersonal relationships, continual personal growth, and a trust-based ambiance within the working environment of the virtual organisation may lead employees to feel an increased sense of well-being. This is because organisations with a supportive culture highlight trust, interactions, collaboration and encouragement among their organisational members, resulting in a more friendly and pleasant organisation (Wallach, 1983; Cameron \& Quinn, 2006; Yiing \& Ahmad, 2009) while those with an innovative culture encourage employees to be more creative, thus continually developing their potential and growth (Ryff \& Singer, 2008). Contrary to common belief, further quantitative analytic results showed that organisational culture was, on the other hand, weakly or insignificantly associated with employees' tacit and explicit knowledge-sharing behaviour in the virtual organisation (see Table 5). Increasing employees' sense of well-being can successfully bridge the gap between organisational culture (e.g. of the bureaucratic, supportive and innovative types) and both employees' tacit and explicit knowledge-sharing behaviour through using ICTs. In short, it appears that employees' sense of well-being can facilitate or improve their knowledge-sharing behaviour through the use of ICTs within the context of the selected virtual organisation in a Chinese culture.

The third contribution of this research is to investigate in depth the gaps between social capital tendency and employees' knowledge-sharing behaviour in a virtual organisation. Although social capital theory has been used previously to shed light on a huge range of social behaviours such as knowledge-sharing behaviour, no research seems to have discussed the impacts of social capital tendency, employees' sense of well-being and Information and Communication Technology (ICT) on employees' knowledge-sharing behaviour from the perspectives of both explicit and tacit knowledge within the more complex context of the virtual organisation. One of the most interesting findings of this research revealed the subtle interplay of employees' sense of well-being, the social capital tendency and their tacit and explicit knowledge-sharing behaviour. Employees, therefore, who are immersed in well-being can be regarded as a critical catalyst in improving not only their tacit knowledge-sharing behaviour, but also explicit knowledge-sharing behaviour through the use of ICTs within the organisation (see Fig. 4). Moreover, this research adds an often overlooked consideration in positive psychology, namely the sense of well-being, as a mediator to explore whether employees who immerse themselves in well-being will exert an influence on the relationship between social capital tendency and knowledge-sharing behaviour. The results reveal that the social capital tendency of employees is positively associated with their sense of well-being; this, in turn, positively affects their 
knowledge-sharing behaviour. Further analytic results showed that adding employees' sense of well-being as a mediating factor can successfully form a bridge that effectively connects social capital tendency and employees' knowledge-sharing behaviour through using ICTs.

The fourth contribution of this research is to deepen insight into the impact of organisational culture on employees' knowledge-sharing behaviour within the context of the virtual organisation in a Chinese culture. When further compared with the analytic results of the first model, which did not consider social capital tendency, the integrated model showed that workplace networks (namely, social capital tendency) seemed to play a more important role in affecting employees' sense of well-being within the virtual organisation in a Chinese cultural context. Hence, employees seemed more concerned about the structure of their social networks and the harmony of the interpersonal relationships of the organisation, rather than their organisational culture, when they concentrated on the pursuit of happiness within the virtual organisation of Taiwanese NGOs, a Chinese cultural context.

\subsection{Practical implications}

The new findings from this study may convince the top managers of virtual organisations to attach considerable importance to employees' knowledge sharing in such organisations in order to enhance the organisation's competitive advantage, and ultimately achieve their goals. This is mainly because the knowledge-sharing behaviour of employees is regarded as a pivotal factor in improving organisational performance (Maciejovsky \& Budescu, 2013). Through using the one-way ANOVA test, the analytic results showed that employees working in company 4 were relatively happier than those in company 1 within the virtual organisation. Hence, in order to promote an appropriate organisational culture and increase employees' sense of well-being, the top managers of a virtual organisation need to take charge of the assimilation of the organisation in order to facilitate cultural changes to support employees' tacit and explicit knowledge-sharing behaviour.

Moreover, the results showed that employees who are treated with greater trust, cooperation, encouragement, creativity and friendliness by the organisation tend to have a greater sense of well-being; this subsequently triggers their motivation to share their knowledge. Hence, employees with a greater sense of well-being seem to enjoy sharing not only their tacit knowledge, but also their explicit knowledge more than others with a lower sense of well-being. They perform such knowledge-sharing behaviour more than their colleagues with a lower sense of well-being and seem more willing to adopt behaviours which help others. Hence, top managers need to create a friendly ambiance of warmth, support and trust for others in the virtual organisation in order to make employees feel a sense of happiness, thus 
improving their knowledge-sharing behaviour.

In addition, through using the one-way ANOVA test, this research found that older employees aged 46-50 (with a mean of 3.68) seemed to be relatively happier than younger employees aged 26-30 (with a mean of 2.98). This showed that age also played an important role in affecting employees' sense of well-being within the virtual organisation. Therefore, managers should not only encourage employees appropriately (especially new and young employees) to take an active part in organisational activities, they should also try to help them blend in with the knowledge-sharing culture of the virtual organisation. Furthermore, having considered that senior employees and those employees who had worked for a long time were more willing to share their knowledge, managers should allocate an appropriate rate of senior employees when considering the establishment and development of a virtual organisation.

Meanwhile, this research has also explored the mediating effect of employees' feeling of well-being on the relationship between organisational culture, and both explicit and tacit knowledge-sharing behaviour. As noted in Table 5, the analytic results showed that the relationship between organisational culture (bureaucratic, supportive and innovative types) and employees' tacit and explicit knowledge-sharing behaviour was significantly and partially mediated by their sense of well-being. This implies that while the organisational culture is still the main factor affecting employees' knowledge-sharing behaviour, employees' sense of well-being will have a mediating effect on this relationship provided that the organisational culture of the organisation has reached a significant level. Without building an appropriate organisational culture within an organisation, there is no point in improving employees' feeling of well-being. Therefore, as long as the building of an appropriate organisational culture reaches a sufficient level, managers of or practitioners in the virtual organisation should pay more attention to considering how to create an appropriate ambiance for employees to feel a sense of well-being while inculcating suitable organisational cultural traits. As more attention is given to the concept of the sense of well-being, as explored and analysed in this research, the managers of the virtual organisation should enact initiatives to create an ambiance surrounded by a sense of well-being for employees in order to improve their knowledge-sharing behaviour. For instance, managers need to think again how to devise more forward-looking organisational strategies or targets so that they closely correspond to their employees' purposes in life. They should also develop more appropriate human resource (HR) practices for their employees in order for them to achieve continual personal growth and ultimately self-realisation. This was noted by Ryff (1989), Ryff and Keyes (1995), Keyes et al. (2002), and Ryff and Singer (2008) who stated that two dimensions of psychological well-being (i.e. personal growth and purpose in life) are the most important factors that make people feel a greater sense of well-being. Moreover, managers in virtual organisations 
urgently need to enact initiatives to overcome or reduce cultural barriers and bring about changes in the underlying organisational culture in order to support the integrated, cross-organisational essence of a virtual organisation in order to enhance their employees' knowledge-sharing behaviour and thus improve their competitive advantage in the market.

More importantly, prior numerous research studies have shown that the social capital tendency of individuals is the first step in their knowledge-sharing behaviour (Wasko \& Faraj, 2005; Hau et al., 2013; Wei, Oh \& Jung, 2011). They have provided robust evidence about how positive social capital tendency is deemed imperative in the successful knowledge-sharing behaviour of individuals (Chiu, Hsu, \& Wang, 2006; Hau et al., 2013). The findings of this research further indicated that employees' sense of well-being exerted a significantly positive mediating impact on the relationship between social capital tendency and knowledge-sharing behaviour. Simultaneously, when compared with organisational culture, workplace networks (i.e. social capital tendency) played a more critical role in affecting employees' sense of well-being; this in turn affected both their tacit and explicit knowledge-sharing behaviour within the context of the selected virtual organisation in a Chinese culture. This implies that even though the social capital tendency of employees still plays the primary role in facilitating employees' knowledge-sharing behaviour, their sense of well-being will have a partially mediating impact on this relationship once social capital tendency has reached a significant level. The findings of the research are in line with the concept of psychological well-being mentioned by Ryff (1989), Ryff and Keyes (1995), and Keyes et al. (2002) who stated that individuals' sense of well-being also relies on the extent to which they develop positive interpersonal relationships with others within the organisation or society. As a result, how to foster better workplace networks is very much worth managers' or practitioners' consideration as a primary factor in facilitating their employees' knowledge-sharing behaviour within the virtual organisation. For instance, the managers of or practitioners in the virtual organisation may consider improving the social values underlying compact mutuality, trust and shared goals among employees in order to gain the benefits of employees' knowledge-sharing behaviour via ICTs. Once the fostering of the social capital tendency of employees reaches a sufficient level, such managers or practitioners should go a step further and create not just a satisfactory, but a trust-based working environment in which their employees are immersed in well-being.

\section{Conclusion}

Drawing on the concept of organisational behaviour based on multilevel perspectives of individuals in organisations (the micro-level), workplace networks in organisations (the meso-level), and organisational systems (the macro-level), this research augments the 
concepts of social capital theory and organisational culture with one pivotal motivator, the sense of well-being, to examine empirically factors concerning knowledge-sharing behaviour through the use of ICTs within the complicated context of a virtual organisation. This study provides managers or practitioners with greater insight into the key role played by employees' sense of well-being in the subtle interplay between social capital tendency, organisational culture and their knowledge-sharing behaviour. These new findings are extremely useful and perhaps even critical in increasing understanding of the mediating role of employees' sense of well-being in the relationships among organisational culture, workplace networks and the different types of knowledge that are shared. Despite its novel finding, this research still has the following limitations which may be answered or overcome by future research. Firstly, since the sense of well-being is a broad and complex construct, the scale used in this study may not sufficiently reflect employees' entire sense of well-being in the complex context of the virtual organisation. Secondly, although this study concentrates on employees' sense of well-being and organisational culture as antecedents to their knowledge-sharing behaviour in the virtual organisation of Taiwanese NGOs, many other factors may be involved. For instance, this study did not analyse the potential moderating effects of, for example, different industrial sectors (e.g., the government sector versus the private sector) or the knowledge-sharing context of the participating organisation. Since the research adopted a cross-sectional combination of a quantitative approach for its data collection, it may not have comprehensively captured the dynamism of the formation of employees' knowledge-sharing behaviour. Moreover, a virtual organisation consists of numerous companies whose employees work in different areas based on different types of organisational culture. This may also influence their willingness to share knowledge. Consequently, to gain greater insight into more in-depth factors concerning individuals' knowledge-sharing behaviour, further research might consider using longitudinal data collection and a participant observation method. This would enable the effects of antecedents of employees' tacit and explicit knowledge-sharing behaviour in a virtual organisation to be explored from a dynamic perspective. To summarise, this study's conclusion does not seek to suggest that employees' negative emotions or lower sense of well-being should be ignored; rather, it proposes that we should do well to consider the mediating impact of employees' sense of well-being on social capital tendency, organisational culture and knowledge-sharing behaviour within such organisations. This is because each type of emotion seems to have its own purpose, and our study suggests that employees with a greater sense of well-being are considerably more likely to share their knowledge in a virtual organisation.

Appendix A: Quantitative measurement instrument (Notes. Items marked (-) should be scored in reverse.)

\begin{tabular}{ll}
\hline Item Question & Reference \\
\hline Employees' sense of well-being: The degree to which an employee feels a sense of well-being in the virtual
\end{tabular}


organisation (Oxford Happiness Questionnaire Short-Form).

WB1 I don't feel particularly pleased with the way I am (-).

WB2 I feel that life is very rewarding.

WB3 I am well satisfied about everything in my life.

WB4 I don't think I look attractive (-).

WB5 I find beauty in some things.

WB6 I can fit in everything I want to.

WB7 I feel fully mentally alert.

WB8 I do not have particularly happy memories of the past (-).

Social Capital Tendency: The degree to which employees are involved in interpersonal relationships in the virtual organisation (Trust=Relational Capital (RC), Social Network Ties=Structural Capital (SC), Shared Goals=Cognitive Capital (CC)).

RC1 I don't trust that my virtual organisational members are worthy to rely

Chow \& Chan, 2008; on (-). Chiu et al., 2006; Hau et

RC2 I know my virtual organisational members will try to help me when I al., 2013 get into difficulties.

RC3 I cannot rely on my virtual organisational members to make my job easier (-).

SC1 I am not very close to my virtual organisational members (-).

Chow \& Chan, 2008;

SC2 I have a very good relationship with my virtual organisational Chiu et al., 2006; Hau et members. al., 2013

SC3 I do not spend a lot of time interacting with members in the virtual organisation (-).

CC1 There is considerable consensus among my virtual organisational

Chiu et al., 2006; Chow members about what is important at work.

\& Chan, 2008; Hau et al.,

CC2 My virtual organisational members are not enthusiastic about achieving 2013 the goals and missions of the organisation (-).

CC3 My virtual organisational members and I always share the same ambitions and goals at work.

Organisational culture: The degree to which an employee recognises the characteristics of organisational culture in his/her organisation (BOC=Bureaucratic Organisational Culture, SOC=Supportive Organisational Culture, Innovative Organisational Culture).

BOC1 My organisation does not strongly emphasise the process of getting Wallach, 1983; Lok \& things done. (-) Crawford, 2004; Yiing \&

BOC2 My organisation follows strictly established systems and operational Ahmad, 2009 procedures.

BOC3 My organisational hierarchy is quite strict.

SOC1 Interaction among members is not important in my organisation. (-) Wallach, 1983; Lok \& 
SOC2 My organisation encourages trial and error, and failure is regarded as learning and an opportunity for improvement.

SOC3 Members in my organisation are sociable and trusting of others.

IOC1 My organisation always encourages members in creativeness.

IOC2 Members of my organisation like to take up a challenge.

IOC3 My organisational members are not enterprising. (-)
Crawford, 2004; Yiing \& Ahmad, 2009

Wallach, 1983; Lok \& Crawford, 2004; Yiing \& Ahmad, 2009

Knowledge Sharing: The extent to which an employee has the willingness to share his/her knowledge in the virtual organisation (TKS=Tacit Knowledge-Sharing Behaviour, EKS=Explicit Knowledge-Sharing Behaviour).

TKS1 I do not often share my experience or know-how from work with my Shao et al., 2012; Hau et virtual organisational members through the use of ICTs. (-) al., 2013

TKS2 I always share my know-where or know-whom at the request of my virtual organisational members through the use of ICTs.

TKS3 I don't like to share my expertise with other members of this virtual organisation through the use of ICTs. (-)

TKS4 I am usually actively involved in discussion on complicated issues through the use of ICTs within the virtual organisation.

EKS1 I am not glad to share my work reports with other members through the use of ICTs within the virtual organisation. (-)

Shao et al., 2012; Hau et al., 2013

EKS2 I like to provide my personal manuals for other members through the use of ICTs within the virtual organisation.

EKS3 I am not pleased to share related official documents with other members of the virtual organisation through the use of ICTs. (-)

EKS4 I will share multimedia files such as media, context, picture or video with members of my organisation through the use of ICTs.

Appendix B: Relevant literature concerning the definition of the virtual organisation integrated in this study

Researcher

Crossman and

Lee-Kelley (2004)

Kasper-Fuehrer and Ashkanasy

DeSanctis and Monge (1999)
Definitions of virtual organisations

The collectives of organisations or individuals which cooperate with each other by utilising Information and Communication Technology (ICT); strategic perspectives are emphasised more than organisational forms.

A virtual organisation is a temporary network of organisations, formed in order to pursue market opportunities, and consisting of a variety of members from independent companies.

Virtual organisations comprise members who come from different independent companies; these join in a dynamic, temporary and cooperative relationship via the use of Information and Communication Technology. 


\begin{tabular}{|c|c|}
\hline Shin (2004) & $\begin{array}{l}\text { A virtual organisation consists of various employees who are from different } \\
\text { companies, and who are located remotely but work together to achieve specific } \\
\text { targets or requirements. }\end{array}$ \\
\hline Byrne (1993) & $\begin{array}{l}\text { A virtual organisation is a temporary team comprising a myriad of companies in } \\
\text { order to reflect rapidly changing marketing requirements. }\end{array}$ \\
\hline $\begin{array}{l}\text { Goldman et al. } \\
\text { (1995) }\end{array}$ & $\begin{array}{l}\text { A virtual organisation consists of a number of companies which cooperate, share } \\
\text { and link together complementary core competencies in order to pursue business } \\
\text { opportunities. }\end{array}$ \\
\hline Squicciarini (2011) & $\begin{array}{l}\text { Virtual organisations are established temporarily and dynamically by numerous } \\
\text { companies or individuals; they can share, combine and pool information, } \\
\text { services and resources to achieve their targets through web applications. }\end{array}$ \\
\hline $\begin{array}{l}\text { Kaihara and Fujii } \\
\text { (2008) }\end{array}$ & $\begin{array}{l}\text { Virtual organisations are a transient alliance of countless companies which } \\
\text { cooperate and share skills, resources and competencies in order to pursue better } \\
\text { business opportunities using integrated Information and Communication } \\
\text { Technology (ICT). }\end{array}$ \\
\hline Lin and Lu (2005) & $\begin{array}{l}\text { The virtual organisation is a combination of geographically distributed, } \\
\text { functionally and culturally diverse entities developed to achieve a collective } \\
\text { goal by pooling their core competencies and resources. At the same time, } \\
\text { members of a virtual organisation rely on Information Technology to coordinate } \\
\text { their activities. }\end{array}$ \\
\hline
\end{tabular}

Appendix C: Cross loadings of each construct

\begin{tabular}{lccccccccc}
\hline & BOC & CC & EKS & IOC & RC & SC & SOC & TKS & WB \\
BOC2 & $\mathbf{0 . 7 7 6}$ & 0.212 & 0.280 & 0.396 & 0.259 & 0.198 & 0.241 & 0.243 & 0.115 \\
BOC3 & $\mathbf{0 . 9 7 9}$ & 0.411 & 0.407 & 0.601 & 0.491 & 0.295 & 0.562 & 0.377 & 0.358 \\
CC1 & 0.405 & $\mathbf{0 . 8 1 8}$ & 0.406 & 0.570 & 0.673 & 0.515 & 0.505 & 0.401 & 0.639 \\
CC2 & 0.232 & $\mathbf{0 . 8 5 8}$ & 0.267 & 0.228 & 0.474 & 0.455 & 0.247 & 0.228 & 0.506 \\
CC3 & 0.329 & $\mathbf{0 . 8 3 1}$ & 0.438 & 0.224 & 0.543 & 0.508 & 0.280 & 0.398 & 0.552 \\
EKS1 & 0.407 & 0.404 & $\mathbf{0 . 9 2 3}$ & 0.461 & 0.515 & 0.471 & 0.471 & 0.723 & 0.533 \\
EKS2 & 0.373 & 0.373 & $\mathbf{0 . 9 2 0}$ & 0.447 & 0.498 & 0.491 & 0.470 & 0.755 & 0.459 \\
EKS3 & 0.325 & 0.377 & $\mathbf{0 . 9 2 6}$ & 0.434 & 0.454 & 0.485 & 0.436 & 0.731 & 0.498 \\
EKS4 & 0.359 & 0.462 & $\mathbf{0 . 8 5 7}$ & 0.423 & 0.465 & 0.604 & 0.405 & 0.826 & 0.517 \\
IOC1 & 0.541 & 0.421 & 0.509 & $\mathbf{0 . 9 5 2}$ & 0.490 & 0.433 & 0.653 & 0.490 & 0.496 \\
IOC2 & 0.568 & 0.414 & 0.467 & $\mathbf{0 . 9 5 7}$ & 0.550 & 0.404 & 0.690 & 0.447 & 0.463 \\
IOC3 & 0.567 & 0.333 & 0.384 & $\mathbf{0 . 9 0 9}$ & 0.499 & 0.347 & 0.648 & 0.361 & 0.401 \\
RC1 & 0.394 & 0.611 & 0.457 & 0.476 & $\mathbf{0 . 8 6 5}$ & 0.581 & 0.578 & 0.386 & 0.616 \\
RC2 & 0.480 & 0.650 & 0.502 & 0.576 & $\mathbf{0 . 9 0 0}$ & 0.616 & 0.525 & 0.487 & 0.701 \\
RC3 & 0.344 & 0.514 & 0.436 & 0.365 & $\mathbf{0 . 8 5 7}$ & 0.508 & 0.433 & 0.415 & 0.496
\end{tabular}




\begin{tabular}{llllllllll} 
SC1 & 0.334 & 0.520 & 0.487 & 0.407 & 0.605 & $\mathbf{0 . 9 3 1}$ & 0.452 & 0.440 & 0.594 \\
SC2 & 0.250 & 0.556 & 0.510 & 0.312 & 0.609 & $\mathbf{0 . 9 4 3}$ & 0.347 & 0.493 & 0.585 \\
SC3 & 0.211 & 0.541 & 0.552 & 0.440 & 0.568 & $\mathbf{0 . 8 5 5}$ & 0.416 & 0.558 & 0.573 \\
SOC1 & 0.419 & 0.346 & 0.488 & 0.680 & 0.503 & 0.398 & $\mathbf{0 . 8 8 2}$ & 0.372 & 0.474 \\
SOC2 & 0.449 & 0.312 & 0.356 & 0.540 & 0.400 & 0.344 & $\mathbf{0 . 8 5 4}$ & 0.309 & 0.364 \\
SOC3 & 0.490 & 0.430 & 0.415 & 0.594 & 0.618 & 0.404 & $\mathbf{0 . 8 5 8}$ & 0.380 & 0.398 \\
TKS1 & 0.319 & 0.427 & 0.786 & 0.427 & 0.487 & 0.554 & 0.401 & $\mathbf{0 . 9 3 2}$ & 0.519 \\
TKS2 & 0.236 & 0.360 & 0.720 & 0.317 & 0.425 & 0.507 & 0.326 & $\mathbf{0 . 9 1 1}$ & 0.415 \\
TKS3 & 0.434 & 0.371 & 0.798 & 0.491 & 0.454 & 0.466 & 0.364 & $\mathbf{0 . 8 9 7}$ & 0.432 \\
TKS4 & 0.371 & 0.353 & 0.765 & 0.470 & 0.434 & 0.461 & 0.413 & $\mathbf{0 . 9 2 8}$ & 0.412 \\
WB2 & 0.229 & 0.472 & 0.475 & 0.321 & 0.518 & 0.471 & 0.346 & 0.457 & $\mathbf{0 . 7 0 0}$ \\
WB3 & 0.376 & 0.608 & 0.454 & 0.543 & 0.672 & 0.510 & 0.513 & 0.409 & $\mathbf{0 . 7 9 5}$ \\
WB4 & 0.318 & 0.571 & 0.467 & 0.479 & 0.561 & 0.456 & 0.447 & 0.409 & $\mathbf{0 . 8 3 1}$ \\
WB5 & 0.155 & 0.491 & 0.407 & 0.247 & 0.494 & 0.494 & 0.239 & 0.382 & $\mathbf{0 . 7 8 0}$ \\
WB6 & 0.247 & 0.522 & 0.448 & 0.383 & 0.504 & 0.509 & 0.407 & 0.371 & $\mathbf{0 . 8 2 2}$ \\
WB7 & 0.149 & 0.548 & 0.375 & 0.357 & 0.535 & 0.574 & 0.339 & 0.322 & $\mathbf{0 . 8 0 1}$ \\
WB8 & 0.262 & 0.504 & 0.404 & 0.291 & 0.508 & 0.502 & 0.315 & 0.312 & $\mathbf{0 . 7 4 8}$ \\
\hline Note & & & & & & & &
\end{tabular}

Note 1: Diagonal bold letters are the cross loading of each construct.

\section{References}

Al-Alawi, A.I., Al-Marzooqi, N.Y., \& Mohammed, Y.F. (2007). Organisational culture and knowledge sharing: Critical success factors. Journal of Knowledge Management, 11(2), 22-42.

Alavi, M., \& Leidner, D.E. (2001). Review: Knowledge management and knowledge management systems: Conceptual foundations and research issue. MIS Quarterly, 25(1), 107-136.

Alwis, R.S., \& Hartmann, E. (2008). The use of tacit knowledge within innovative companies: Knowledge management in innovative enterprises. Journal of Knowledge Management, 12(1), 133-147.

Argyle, M., Martin, M., \& Crossland, J. (1989). Happiness as a function of personality and social encounters. In Forgas, J. P. and Innes, J. M. (Eds.), Recent advances in social psychology: An international perspective (189-203). North-Holland: Elsevier.

Barclay, D., Thompson, R., \& Higgins, C. (1995). The partial least squares (PLS) approach to causal modeling: Personal computer adoption and use an illustration. Technology Studies, 22(2), 285-309.

Baron, N.S., \& Kenney, D.A. (1986). The moderator - mediator variable distinction in social psychological research: Conceptual, strategic, and statistical considerations. Journal of 
Personality and Social Psychology, 51(6) 1173-1182.

Birkinshaw, J. (2001). Why is the knowledge management so difficult? Business Strategy Review, 12 (1), 11-18.

Boehm, J.K., \& Lyubomirsky, S. (2008). Does happiness promote career success? Journal of Career Assessment, 16(1), 101-116.

Borman, W.C., Penner, L.A., Allen, T.D., \& Motowidlo, S.J. (2001). Personality predictors of citizenship performance. International Journal of Selection and Assessment, 9(1/2), 52-69.

Brown, R.B., \& Woodland, M.J. (1999). Managing knowledge wisely: A case study in organizational behavior. Journal of Applied Management Studies, 8(2), 175-198.

Burn, J.M., \& Ash, C. (2000). Knowledge management strategies for virtual organisations. Information Resources Management Journal, 13(1), 15-23.

Camic, C. (1986). The Matter of Habit. The American Journal of Sociology, 91(5), 1039-1087.

Carr, A. (2004). Positive psychology: The science of happiness and human strengths. London: Routledge.

Cameron, K.S., \& Quinn, R.E. (2006). Diagnosing and changing organizational culture: based on the competing values framework. Hoboken, NJ: Jossey-Bass.

Chen, I.C., Ng, H.F., \& Li, H.H. (2012). A multilevel model of patient safety culture: cross-level relationship between organizational culture and patient safety behavior in Taiwan's hospitals. The International Journal of Health Planning and Management, 27(1), 65-82.

Chin, W.W. (1998a). Issues and opinion on structural equation modeling. MIS Quarterly, 22(1), vii-xvi.

Chin, W.W. (1998b). The partial least squares approach to structural equation modeling. In Marcoulides, G.A. (Ed.), Modern Methods for Business Research (pp. 295-336). Mahwah, NJ: Lawrence Brlbaum Associates.

Chin, W.W., Marcolin, B.L., \& Newsted, P.R. (2003). A partial least squares latent variable modeling approach for measuring interaction effects: Results from a Monte Carlo simulation study and an electronic mail emotion/adoption study. Information Systems Research, 14(2), 189-217.

Chiu, C.M., Hsu, M.H., \& Wang, E.T. G. (2006). Understanding knowledge sharing in virtual communities: An integration of social capital and social cognitive theories. Decision Support Systems, 42(3), 1872-1888.

Chow, W.S., \& Chan, L.S. (2008). Social network, social trust and shared goals in organisational knowledge sharing. Information \& Management, 45(7), 458-465.

Curran, P.J., West, S.G., \& Finch, J.F. (1996). The robustness of test statistics to nonnormality and specification error in confirmatory factor analysis. Psychological Methods, 1(1), 
16-29.

DeNeve, K.M., \& Cooper, H. (1998). The happy personality: A metaanalysis of 137 personality traits and subjective well-being. Psychological Bulletin, 124, 197-229.

Davenport, T.H. (1994). Saving IT’s soul: Human-centered information management. Harvard Business Review, 119-131.

Davenport, T.H., \& Prusak, L. (1998). Working Knowledge: How Organizations Manage What They Know. Boston: Harvard Business School Press.

Diener, E., \& Biswas-Diener, R. (2002). Will money increase subjective well-being? A literature review and guide to needed research. Social Indicators Research: 57(2), 119-169.

Ding, W.Y. (2011). A historical development perspective on the formation of Taiwan's Farmers Association features. Journal of Farmers' Organizations, 17, 93-115.

Dixon, N.M. (2000). Common knowledge: how companies thrive by sharing what they know. Boston: Harvard Business School Press.

Drucker, P.F. (1990) Managing the non-profit organizations: Practices and principles, New York: Harper Collins Publishers.

Fornell, C., \& Larcker, D. (1981). Evaluating structural equation models with unobservable variables and measurement error. Journal of marketing research, 18(1), 39-50.

Gefen, D., Rigdon, E.E., \& Straub, D. (2011). An update andextension to SEM guidelines for administrative and socialscience research. MIS Quarterly, 35(2), iii-xiv.

George, J.M. (1991). State or trait: Effects of positive mood on prosocial behaviors at work. Journal of Applied Psychology, 76(2), 299-307.

George, J.M., \& Brief, A.P. (1992). Feeling good-doing good: A conceptual analysis of the mood at work-organizational spontaneity relationship. Psychological Bulletin, 112(2), 310-329.

Goldman, L., Nagel, R.L., \& Preiss, K. (1995). Agile competitors and virtual organisations Strategies for Enriching the Customer, New York: Van Nostrand Reinhold.

Hau, Y.S., Kim, B., Lee, H., \& Kim, Y.G. (2013). The effects of individual motivations and social capital on employees' tacit and explicit knowledge sharing intentions. International Journal of Information Management, 33(2), 356-366.

Headey, B.W., \& Wearing, A.J. (1989). Personality, life events and subjective wellbeing: towards a dynamic equilibrium model. Journal of Personality and Social Psychology, 57, 731-39.

Helliwell, J.F., \& Putnam, R. (2004). The social context of well-being”, Philosophical Transactions of the Royal Society London, 359(1449), 1435-1446.

Hills, P., \& Argyle, M. (2002). The Oxford Happiness Questionnaire: a compact scale for measurement of psychological well-being. Personality and Individual Differences, 33(7), 1073-1082. 
Holste, J.S., \& Fields, D. (2010). Trust and tacit knowledge sharing and use. Journal of Knowledge Management, 14(1), 128-140.

Hong, D., Suh, E. \& Koo, C. (2011). Developing strategies for overcoming barriers to knowledge sharing based on conversational knowledge management: A case study of a financial company. Expert Systems with Applications, 38(12), 14417-14427.

Huang, J.L. (1992). Adjustment of Taiwanese agricultural financial system - based on Financial liberalization and internationalization. Taiwan Community Financial Journal, 26: 145-173.

Jau, J.J. (2014). NGO, in simple terms. [Online]. Available from: http://www.taiwanngo.tw/files/15-1000-17458,c104-1.php (Accessed: 4 June 2014).

Jo, S.J., \& Joo, B.K. (2011). Knowledge sharing: The influences of learning organization culture, organizational commitment, and organizational citizenship behaviors. Journal of Leadership \& Organizational Studies, 18(3), 353-364.

Johnson-Miles, C.W. (2007). Universal Nexus: Secret notes on the sum of life, US: Johnson-mils.

Joreskog, K.G., \& Wold, H. (1982). The ML and PLS Techniques for Modeling with Latent Variables: Historical and Comparative Aspects. In Systems Under Indirect Observation: Causality Structure and Prediction, K. G. Joreskog and H. Wold (eds.). North Holland, Amsterdam, 263-270.

Joshi, K.D., Sarker, S., \& Sarker, S. (2007). Knowledge transfer within informationsystems development teams: examining the role of knowledge source attributes. Decision Support Systems, 43(2), 322-335.

Jung, C.G. (1933). Modern man in search of a soul (Dell, W.S. and Baynes, C.F., Trans.). New York: Hartcourt, Brace and World.

Keyes, C.L.M. (1998). Social well-being. Social psychology quarterly, 61(2), 121-140.

Keyes, C.L.M., Shmotkin, D., \& Ryff, C.D. (2002). Optimizing well-being: the empirical encounter of two traditions. Journal of Personality and Social Psychology, 82(6), 1007-1022.

Khan, M.A., \& Afzal, h. (2011). High level of education builds up strong relationship between organisational culture and organisation performance in Pakistan. The International Journal of Human Resource Management, 22(7), 1387-1400.

Koberg, C.S., \& Chusmir, L.H. (1987). Organizational culture relationships with creativity and other job-related variables. Journal of Business Research, 15(5), 397-409.

Lai, M.F., \& Lee G.G. (2007). Risk-avoiding cultures toward achievement of knowledge sharing. Business Process Management Journal, 13(4), 522-537.

Langton, N., Robbins, S.P., \& Judge, T.A. (2012). Organizational Behaviour: Concepts, Controversies, Applications ( $6^{\text {th }}$ ed.). Canada, Toronto: Pearson.

Lee, J.C., Shiue, Y.C., \& Chen, C.Y. (2016). Examining the impacts of organisational culture 
and top management support of knowledge sharing on the success of software process improvement. Computers in Human Behaviour, 54, 462-472.

Li, Y.C. (2004). Examining the effect of organization culture and leadership behaviours on organizational commitment, job satisfaction, and job performance at small and middle-sized firms of Taiwan. Journal of American Academy of Business, 5(1/2), 432-438.

Lin, H.F. (2007a). Effects of extrinsic and intrinsic motivation on employee knowledge sharing intentions. Journal of Information Science, 32(2), 135-149.

Lin, H.F. (2007b). Knowledge sharing and firm innovation capability: An empirical study. International Journal of Manpower, 28(3/4), 315-332.

Leonardi, P.M., \& Treem, J.W. (2012). Knowledge management technology as a stage for strategic self-presentation: Implications for knowledge sharing. Information and Organisation, 22(1), 37-59.

Lettieri, E., Borga, F., \& Savoldelli, A. (2004). Knowledge management in non-profit organisations. Journal of Knowledge Management, 8(6), 16-30.

Lin, H.F. (2007). Knowledge sharing and firm innovation capability: an empirical study. International Journal of Manpower, 28(3/4), 315-332.

Liu, P., Raahemi, B., \& Benyoucef, M. (2011). Knowledge sharing in dynamic virtual enterprises: A socio-technological perspective. Knowledge-Based Systems, 24(3), 427-443.

Locke, E.A., \& Latham, G.P. (2006). New directions in goal-setting theory. Current Directions in Psychological Science, 15(5), 265-268.

Lok, P., \& Crawford, J. (2004). The effect of organisational culture and leadership style on job satisfaction and organisational commitment: A cross-national comparison. Journal of Management Development, 23(4), 321-338.

Lyubomirsky, S., Sheldon, K.M., \& Schkade, D. (2005). Pursuing happiness: The architecture of sustainable change. Review of General Psychology, 9(2), 111-131.

Maciejovsky, B., \& Budescu, D.V. (2013). Markets as a structural solution to knowledge-sharing dilemmas. Organizational Behavior and Human Decision Processes, 120(2), 154-167.

Maslow, A. H. (1968). Toward a psychology of being ( $2^{\text {nd }}$ ed.). New York: Van Nostrand.

McDermott, R., \& O’Dell, C. (2001). Overcoming cultural barriers to sharing knowledge. Journal of Knowledge Management, 5(1), 76-85.

Meier. S. \& Stutzer, A. (2008). Is volunteering rewarding in itself? Economica, London School of Economics and Political Science, 75(297), 39-59.

Midlarsky, E., \& Kahana, E. (2007). Altruism, well-being, and mental health in late life (56-69, in Stephen Post, ed.). Altruism and Health. New York: Oxford University Press.

Miller, D.L., \& Karakowsky, L. (2005). Gender influences as an impediment to knowledge 
sharing: when men and women fail to seek peer feedback. The Journal of Psychology, 139(2), 101-118.

Mooradian, T.A., Renzl, B., \& Matzler, K. (2006). Who trusts? Personality, trust and knowledge sharing. Management Learning, 37(4), 523-540.

Nonaka, I. (1991). The knowledge-creating company. Harvard Business Review, 69(6), 96-104.

Nonaka, I., \& Krog, G.V. (2009). Tacit knowledge and knowledge conversion: Controversy and advancement in organisational knowledge creation theory. Organisation Science, 20(3), 635-652.

Nonaka, I., \& Takeuchi, H. (1995). The Knowledge-Creating Company. How Japanese Companies Create the Dynamics of Innovation. Oxford: Oxford University Press.

Nonaka, I., Toyama, R., \& Knno, N. (2000). SECI, Ba and Leadership: Aunified model of dynamicknowledge creation. Long Range Planning, 33(1), 5-34.

Nunnally, J.C. (1978). Psychometric Theory, New York: McGraw-Hill.

Organ, D.W. (1988). Organizational Citizenship Behavior: The good soldier syndrome. Lexington, MA: Lexington Books.

Park, S.H., \& Luo, Y. (2001). Guanxi and organizational dynamics: Organizational networking in Chinese firms. Strategic Management Journal, 22, 455-477.

Pfeffer, J., \& Sutton, R. (1999). Knowing "What" to do is not enough: turning knowledge into action. California Management Review, 42(1), 83-108.

Podsakoff, P.M., MacKenzie, S.B., Lee, J.Y., \& Podsakoff, N.P. (2003). Common method biases in behavioral research: A critical review of the literature and recommended remedies. Journal of Applied Psychology, 88(5), 879-903.

Podsakoff, P.M., \& Organ, D.W., 1986. Self-reports in organizational research: Problems and prospects. Journal of Management, 12(4): 531-544.

Polanyi, M. (1958 \& 1962). Personal knowledge: toward a post-critical philosophy. London: Routledge and and Kegan Paul Ltd.

Polanyi, M. (1966). The tacit dimension. Doubleday, Garden City, NY.

Rastogi, P.N. (2000). Knowledge management and intellectual capital - The new virtuous reality of competitiveness. Human System Management, 19(1), 39-48.

Ringle, C., Wende, S., \& Will, A. (2005). Smart PLS 2.0 (Beta). Hamburg, [Online]. Available from: http://www.smartpls.de.

Robbins, M., Francis, L.J., \& Edwards, B. (2010). Happiness as stable extraversion: internal consistency reliability and construct validity of the Oxford Happiness Questionnaire among undergraduate students. Current Psychology, 29(2), 89-94.

Robinson, J., \& Shaver, P.R. (1973). Measures of social psychological attitudes. Ann Arbor, MI: Institute for Social Research.

Post, S.G. (2005). Altruism, happiness, and health: It's good to be good. International Journal 
of Behaviour Medicine, 12(2), 66-77.

Ruggles, R. (1998). The state of the notion: knowledge management in practice. California Management Review, 40(3), 80-89.

Ryan, R.M., \& Deci, E.L. (2001). On happiness and human potentials: A review of research on hedonic and eudaimonic well-being. Annual Review of Psychology, 52, 141-166.

Ryff, C.D., \& Singer, B.H. (2008). Know thyself and become what you are: A eudaimonic approach to psychological well-being. Journal of Happiness Studies, 9(1), 13-39.

Ryff, C.D., \& Keyes, C.L. (1995). The structure of psychological well-being revisited. Journal of Personality and Social Psychology, 69(4), 719-727.

Ryff, C.D., \& Singer, B.H. (2008). Know thyself and become what you are: A eudaimonic approach to psychological well-being. Journal of Happiness Studies, 9(1), 13-39.

Saari, L.M., \& Judge, T.A. (2004). Employee attitudes and job satisfaction. Human Resource Management, 43(4), 395-407.

Schein, E.H. (1985). Organisational culture and leadership: a dynamic view. San Francisco: Jossey-Bass.

Schein, E.M. (2004). Organizational culture and leadership. (3rd. ed.). Jossy-Bass.

Seligman, M.E.P., \& Csikszentmihalyi, M. (2000). Positive psychology: An introduction. American Psychologist, 55(1), 5-14.

Shao, Z., Feng, Y., \& Liu, L (2012). The mediating effect of organizational culture and knowledge sharing on transformational leadership and Enterprise Resource Planning systems success: An empirical study in China. Computers in Human Behavior, 28(6), 2400-2413.

Shanafelt, T.D., West. C., Zhao, X., Novotny, P., Kolars, J., Habermann, T. \& Sloan, J (2005). Relationship between increased personal well-being and enhanced empathy among internal medicine residents. Journal of General Internal Medicine, 20(7), 559-564.

Sharma, B.P., Singh, M.D., \& Neha (2012). Knowledge Sharing Barriers: An Approach of Interpretive Structural Modeling. IUP Journal of Knowledge Management, X(3), 35-52.

Sheldon, K. M., \& Bettencourt, B. A. (2002). Psychological needs and subjective well-being in social groups. British Journal of Social Psychology, 41, 25-38.

Simonton, D.K., \& Baumeister, R.F. (2005). Positive psychology at the Summit. Review of General Psychology, 9(2), 99-102.

Squicciarini, A.C., Paci, F., \& Bertino, E. (2011). Trust establishment in the formation of virtual organisations. Computer Standards and Interfaces, 33(1), 13-23.

Stenmark, D. (2000/01). Leveraging tacit organisational knowledge. Journal of Management Information Systems, 17(3), 9-24.

Suppiah, V., \& Sandhu, M.S. (2011). Organisational culture's influence on tacit knowledge-sharing behaviour. Journal of Knowledge Management, 15(3), 462-477 
Thomas, M.R., Dyrbye, L.N., Huntington, J.L., Lawson, K.L., Novotny, P.J., Sloan, J.A., \& Shanafelt, T.D. (2007). How do distress and well-being relate to medical student empathy? A multicenter study. Journal of General Internal Medicine, 22(2), 177-183.

Tong, J., \& Mitra, A. (2009). Chinese cultural influences on knowledge management practice. Journal of Knowledge Management, 13(2), 49-62.

Von Krogh, G. (1998). Care in knowledge creation. California Management Review, 40(3), 134-153.

Wallach, E.J. (1983). Individuals and organisations: the cultural match. Training and Development Journal, 37(2), 29-36.

Wang, W.T., \& Hou, Y-P. (2015). Motivations of employees' knowledge sharing behaviours: A self-determination perspective. Information and Organisation, 25, 1-26.

Wasko, M.M., \& Faraj, S. (2000). It is what one does: Why people participate and help others in electronic communities of practice. Journal of Strategic Information Systems, 9(2-3), 155-173.

Wasko, M.M., \& Faraj, S. (2005). Why should I share? Examining social capital and knowledge contribution in electronic networks of practice. MIS Quarterly, 29(1), 35-57.

Watson, S., \& Hewett, K. (2006). A multi-theoretical model of knowledge transfer in organizations: Determinants of knowledge contribution and reuse. Journal of Management Studies, 43(2), 141-173.

Wi, h., Oh, S., \& Jung, M. (2011). Virtual organisation for open innovation: Semantic web-based inter-organisational team formation. Expert Systems with Applications, 38(7), 8466-8476.

Wixom, B.H., \& Watson, H.J. (2001). An empirical investigation of the factors affecting data warehouse success. MIS Quarterly, 25(1), 17-41.

Yiing, L.H., \& Ahmad, K.Z.B. (2009). The moderating effects of organizational culture on the relationships between leadership behaviour and organizational commitment and between organizational commitment and job satisfaction and performance. Leadership and Organization Development Journal, 30(1), 53-86.

Yip, W., Subramanian, S. V., Mitchell, A. D., Lee, T. S., Wang, J., \& Kawachi, I. (2007). Does social capital enhance health and well-being? Evidence from rural China. Social Science \& Medicine, 64(1), 35-49. 